\title{
IMPACTOS DO PRONAF NO SUDESTE PARAENSE: AVALIAÇÃO DA SUSTENTABILIDADE DE AGROECOSSISTEMAS FAMILIARES ${ }^{1}$
}

\author{
Luis Mauro Santos Silva ${ }^{2}$ \\ Sérgio Roberto Martins ${ }^{3}$
}

\section{RESUMO}

O Território Sudeste do estado do Pará mantém a agricultura familiar como sua categoria social mais representativa. Ao longo das últimas três décadas, esta região assumiu o caráter de fronteira agrícola amazônica e sua ocupação se deu através de políticas de incentivos fiscais, sendo estas indutoras de uma forte dinâmica de desmatamento e ocupação empresarial via pecuária extensiva. A partir da década de 1990, uma nova política agrária assegurou significativo volume de recursos dedicados exclusivamente a esta categoria social. O presente estudo reflete sobre as dimensões social, ambiental e técnicoeconômica das unidades familiares, tomando como contexto o ambiente do assentamento rural sob a égide da atual política agrária nacional. A unidade de estudo assumida é o agroecossistema familiar. O MESMIS (Marco de Avaliação de Sistemas de Manejo Incorporando Indicadores de Sustentabilidade) norteou a análise mediante um conceito de sustentabilidade construido a partir de uma noção dos atores envolvidos no contexto local (técnicos e familias assentadas). Dentre os melhores desempenhos observados ${ }^{(1)}$, se destaca a opção pela diversidade de atividades produtivas. Os agroecossistemas mais frágeis estão associados a uma continuidade da pecuária extensiva como projeto familiar, reproduzindo a necessidade progressiva do desmatamento de novas áreas.

Palavras-chave: Amazônia brasileira, Avaliação, Indicadores, Assentamentos Rurais.

1 Artigo extraido da tese de doutoramento do primeiro autor.

2 Eng. Agr., Dr. Docente da Universidade Federal do Pará/NCADR/LASAT. Rua Frei Raimundo Lambezart, 2454, Apto. 09-A, Bairro Cidade Nova; CEP: 68.501-680; Marabá - PA, Brasil; Imsilva@ufpa.br

3 Eng. Agr., Dr. Docente da Universidade Federal de Santa Catarina/ENS; Rua Prof'. Emilia Schimidt, $\mathrm{n}^{\circ}$ 42, Bairro Bom Abrigo; CEP: 88085-270; Florianópolis-SC, Brasil; martinss@ brturbo.com.br

Agr. Fam. Belém n 9 p. 39-80 2009 


\section{ABSTRACT}

The southeast territorium from the state Para maintains the familiar agriculture as the most representative social category. During the last three decades, this region assumes the character of an amazonian agriculture front and its occupation was through politics of fiscal incentives, which were inducement of a strong dinamic of deforestation and enterprising occupation with an extensive cattle production. Since the 90 th, a new agrarian politic assegured a significative amount of resources dedicated exclusively to this social category. The present research reflects the social and technicoeconomical dimensions of the familiar unities and the environmental one, based on the context of the the rural assettlement's environment under the protection of the national agrarian politic of today. The research unity assumed is the familiar agroecossystem. The MESMIS (Mark for evaluation of the Systems for Management of the natural resources incorporating Indicators of Sustainability) norted the analysis through a sustainable concept based on a notion constructed by the envolved actors of the local context (technics and assettled families). Among the best observed performances (1), stand out the diversity option from the productive activities. The most fragile agroecosystems are associated with the continuity of the extensive cattle production as a familiar project, which reproduces the progressive necessity of deforestation of new areas.

Keywords: Brazilian Amazonia, Indicators, Valuation, Rural Assettlement's.

\section{INTRODUÇÃO}

Historicamente, inúmeras tentativas de integrar a Amazônia às estratégias desenvolvimentistas causaram (e ainda causam) mudanças ambientais, sociais e econômicas. Além da exploração madeireira e mineral, o investimento que ganhou destaque foi a pecuária extensiva, envolvida diretamente no processo de substituição do contingente humano, além da redução progressiva da diversidade natural. 
Impactos do pronaf no sudeste paraense: Avaliação da sustentabilidade de agroecossistemas familiares

O aumento da pressão sobre a região amazônica tem sido objeto de preocupação de diversos autores, que apontam diferentes possibilidades de pensar sobre o futuro da maior floresta tropical do mundo. Os cenários sobre o seu futuro vão desde o investimento em tecnologias de intensificação produtiva nas regiões ditas mais aptas para a agricultura, preservando e valorizando economicamente as zonas menos impactadas pelo processo produtivo capitalista (KITAMURA, 1994; HOMMA, 2005). Também se destacam posturas mais preservacionista nas regiões pouco alteradas e a reconstituição das áreas já alteradas (VIEIRA, et al., 2005).

Contudo, pensar no futuro desta região é interferir em um ambiente de riqueza social ainda pouco conhecida (LIMA e POZZOBON, 2005). As complexas interações entre recursos humanos e naturais se traduzem em um mosaico social que confronta, no mesmo espaço, indígenas, caboclos, migrantes, empresários rurais, urbanos etc. Mesmo assim, o processo de "modernização via urbanização" vem se dando de forma quase inexorável, ampliando as dúvidas sobre quais sistemas produtivos serão capazes de se consolidar.

Ao longo de todo o processo de intervenção econômica, seja pelo Estado ou capital privado, tem predominado a idéia de modelos homogêneos, desconsiderando as peculiaridades dos distintos recursos sociais e ambientais. A Amazônia guarda enorme heterogeneidade e tudo aponta para que o futuro das zonas menos antropizadas dependa, diretamente, de uma melhor compreensão das formas de exploração engendradas nas regiões que sofrem maior pressão sobre os recursos naturais.

O território sudeste ${ }^{4}$ do estado do Pará, em particular, carece de estudos mais amplos e aprofundados sobre a evolução da agricultura, principalmente pela forte antropização induzida pelo Estado. E neste contexto, a população tem convivido com diferentes ciclos de exploração desde as formas menos impactantes, através das primeiras populações indígenas a 3.500 a.C. até o atual estado de declínio das áreas florestadas e predominância de pastagens cultivadas (d'Ans, 1982 citado por DE REYNAL, 1999).

4 O território do sudeste do Pará compõe uma centena de territórios já reconhecidos pela Secretaria de Desenvolvimento Territorial (SDT), do Ministério de Desenvolvimento Agrário (MDA). É formado por sete municípios: Marabá, Itupiranga, Parauapebas, Eldorado dos Carajás, São João do Araguaia, São Domingos do Araguaia e Nova Ipixuna. 
Apesar de ainda pouco presente no espaço amazônico, a pesquisa agronômica tem mantido um caráter experimental, que pouco consegue valorizar as experiências autóctones. Os agroecossistemas ${ }^{5}$ familiares têm sido precipitadamente considerados atrasados do ponto de vista tecnológico e, portanto, ineficientes para um incremento produtivo dito moderno. Praticamente inexistem registros de pesquisa sobre referenciais técnicos regionalizados, dificultando a busca de novos parâmetros e ferramentas diferenciadas de análise agronômica. Assim, impõem-se fortes limites para uma re-leitura da importância da Amazônia, com uma perspectiva diferenciada de desenvolvimento.

Até a década de 1980 , à revelia das políticas públicas oficiais, a agricultura familiar deste território conseguiu manter um protagonismo político, social e econômico, em que pese os limites impostos pelo agravamento dos problemas ambientais (desmatamento) e sociais (conflitos fundiários) e econômicos (baixa capacidade de investimento).

Apenas na década de 1990 o governo federal incluiu estes atores no foco de investimento produtivo, garantindo recursos significativos na regularização fundiária, em atividades agropecuárias e assistência técnica. Mesmo com uma grande abrangência regional do Programa Nacional de Fortalecimento da Agricultura Familiar (PRONAF) ${ }^{6}$ percebe-se que os primeiros resultados ainda se mostram pouco animadores para a sustentabilidade dos agroecossistemas familiares beneficiados.

Os poucos estudos sobre o impacto destas políticas não têm conseguido articular as diversas dimensões impactadas pelas intervenções externas no agroecossistema familiar. Alguns se concentram no aspecto organizacional, financeiro (TURA et. ali., 2000) e do funcionamento dos serviços de assessoria técnica (OLIVEIRA, 2005). Recentemente, estudos se lançaram em uma tentativa de avaliações mais amplas sobre a agricultura

5 Agroecossistemas é aqui considerado como unidades familiares de produção que garantem o consumo e renda; é espaço da vida social e utilizam principalmente o trabalho familiar para desenvolver suas atividades produtivas. Aqui tomamos o conceito construido por ASTIER et. al., 2002), assumindo como sinônimos os termos agroecossistemas e sistemas de produção ou unidade familiar de produção, onde além de espaço produtivo, se faz necessária a compreensão de sua complexidade sócio-produtiva.

6 Criado através do Decreto Lei n 1.946 em 28.07.1996, o Programa Nacional de Fortalecimento da Agricultura Familiar - PRONAF tem como finalidade a promoção do desenvolvimento sustentável do segmento rural constituido pelos agricultores familiares, de modo a propiciarlhes o aumento da capacidade produtiva, a geração de empregos e a melhoria de renda. 
Impactos do pronaf no sudeste paraense: Avaliação da sustentabilidade de agroecossistemas familiares

familiar, envolvendo mais dimensões da sustentabilidade (COSTA, 2006; SILVA, 2007; SILVA, 2008.

Devido a esta dificuldade, pouco se tem avançado nas reflexões sobre as possibilidades de consolidação de agroecossistemas com base ampla de sustentabilidade (ambiental, social e econômica), seja através de intervenção da Assistência Técnica e Extensão Rural (ATER) ou por iniciativas próprias das familias locais.

Neste sentido, o presente estudo se concentrou em aspectos de uma avaliação objetiva dentro de indicadores específicos definidos para tal realidade. Buscou-se privilegiar as dimensões ambiental, econômica e social, focando algumas potencialidades e limites destes agroecossistemas, buscando visualizar novos elementos de reflexão para futuras políticas públicas regionais. A base desta avaliação está no estudo de Silva (2008) e outras aplicações metodológicas realizadas em outras regiões do Brasil com a mesma metodologia (VERONA, 2008; CORRÊA, 2007), mas todas inspiradas no MESMIS, metodologia descrita mais adiante.

\section{DE QUAL SUSTENTABILIDADE FALAMOS?}

Nas últimas décadas, o uso do termo sustentabilidade tem sido vulgarizado. $\mathrm{O}$ mesmo tem assumido, na maioria das vezes, um caráter de mera adjetivação de uma evolução do atual modelo de desenvolvimento. Sua vasta significação etimológica ${ }^{7}$ tem servido tanto para criticar quanto para legitimar o paradigma do crescimento econômico. De um lado, esse termo é utilizado para ressaltar as conseqüências negativas engendradas especialmente nas dimensões ambientais e sociais do desenvolvimento, seja na escala local ou global. De outro, surge em forma de políticas compensatórias, cuja sustentabilidade se encerra na manutenção da atual matriz técnico-econômica por meio da minimização de catástrofes e desigualdades sociais extremas precipitadas nas últimas décadas.

Boa parte das reflexões ligadas a esse tema (LUTZENBERGER, 1980; MONTIBELLER, 2004; CLÓVIS CAVALCANTE, 2001; CARSON, 2005; VEIGA, 2005; LEFF, 2006, MARTINS, 1997, entre outras) apontam a

7 Etimologicamente, a palavra sustentável significa: at. Sustento, sustentar, suportar, resistir, continuar, suster; defender, equilibrar, proteger; apoiar; firmar, manter, conservar, cuidar; auxiliar, vir em socorro; alimentar, manter; sofrer, suportar, resistir a; diferir, adiar. 
impossibilidade de manter os atuais índices de crescimento econômico e, ao mesmo tempo, democratizar bens e serviços com bases menos deletérias nas suas relações com os biomas naturais. Ainda destacam que para tornar esta "engenharia" possivel, é necessário uma revisão de conceitos e das formas de intervenção humana junto aos recursos naturais ainda disponiveis.

Em outras palavras, o termo sustentabilidade traz como premissa básica sair de uma enviesada consolidação econômica para uma compreensão maior das complexas relações entre sociedade e natureza.

Nas reflexões de Leff (2006), se observa a necessidade de construir um novo sistema de regras de pensamento e ação que esteja além da esfera econômica. Ele propõe uma racionalidade ambiental em substituição à racionalidade econômica. Desta forma, se qualificaria alguns métodos analíticos para uma melhor compreensão dos processos naturais e suas interações com os saberes locais. Esta transição para uma suposta racionalidade evoluída - a ambiental - passaria pelo engajamento acadêmico no pensamento complexo, que nos livraria da visão disciplinar e potencializaria os conhecimentos provenientes do diálogo entre as racionalidades econômicas e a de um novo paradigma emergente.

Se por um lado há um crescente acúmulo de contribuições teóricas sobre sustentabilidade, por outro ainda se observa certa dificuldade na operacionalidade dos conceitos. Isto induz ao pensamento de que as estratégias de desenvolvimento nem sempre levam em consideração os anseios dos atores sociais a quem estas supostamente são dirigidas. Martins (2008) destaca que "mais importante do que buscar alternativas para o desenvolvimento sustentável de um sistema, é poder perceber de forma sistêmica o processo de desenvolvimento sustentável".

Para as ciências agrárias, o advento da agricultura simbolizou o marco fundamental do desenvolvimento humano. Porém, assim como advertem Mazoyer e Roudat (1997), Ehlers (1999), entre outros, desde o advento da exploração agrícola de forma sedentária, há aproximadamente dez mil anos, a transformação das relações entre sociedade e natureza caminhou para a consolidação de dinâmicas muito antagônicas.

Transportando para os dias atuais, a noção de sustentabilidade adotada pelas ciências agrárias ainda privilegia a dimensão econômica sobre as demais dimensões nas estratégicas de desenvolvimento. Porém, recentemente várias propostas acadêmicas passaram a considerar as múltiplas dimensões 
do desenvolvimento. A complexidade da realidade e a abordagem sistêmica passaram a povoar fóruns acadêmicos e não-acadêmicos. Podemos tomar como exemplos a consolidação da Associação Brasileira de Agroecologia (ABA) e da Articulação Nacional de Agroecologia (ANA). Além destes fóruns, vários programas de graduação e pós-graduação ligados às instituições federais incluíram esta temática em seus conteúdos. E estas mudanças têm contribuido com uma reflexão mais aprofundada sobre uma noção mais ampla de sustentabilidade na agricultura.

Para esta complexidade ser apreendida e abordada pela academia, Esteves de Vasconcellos (2002) e Morin (2005) ressaltaram que é preciso reconhecer o predomínio de um paradigma simplificador. Esta simplificação do universo tem a ordem como uma lei fundamental que expulsa toda a possibilidade de desordem. E este princípio UNO (simplicidade) separa o que está ligado (disjunção) ou unifica o que é diverso (redução). Esta lei da ordem absoluta perdeu sentido desde o século XIX, através da universalização da segunda Lei da Termodinâmica (entropia). Porém, mesmo com o advento de um novo pensamento científico (o complexo), a simplificação não deixou de ser necessária, contanto que seja relativizada, ou seja, contextualizada.

Funtowicz e De Marchi (2000) acreditam ainda que uma aplicação transdisciplinar dos conhecimentos acumulados aponte possibilidades reais de visualizar novos rumos para o pensamento científico. O certo é que ainda existem muitas dificuldades para uma real mudança paradigmática, mesmo estando em curso a construção de novas compreensões sobre sustentabilidade.

Esta verdadeira "cortina de fumaça" criada em torno de termos considerados ainda como revolucionários e vanguardistas (Desenvolvimento Sustentável e Sustentabilidade) coloca dúvidas sobre sua efetividade como ideia-força basilar para um paradigma sócio-ambiental do mundo moderno. Ainda não está claro para muitos teóricos se estes conceitos ficam apenas sob a responsabilidade das ciências (normal e/ou pós-normal) ou se ela deve ser fruto de um amplo diálogo de distintos saberes, contextos e escalas (ALMEIDA, 2004).

Assim, do latifúndio ao minifúndio; do rico ao pobre; do urbano ao rural; todos acreditam no advento da sustentabilidade para melhorar ou garantir suas condições de vida. 
Diante de tanta novidade na visão de um novo desenvolvimento, estas proposições parecem convergir para uma revalorização dos conhecimentos não-acadêmicos (autóctones) exigindo assim o real protagonismo das sociedades e suas idiossincrasias. Possivelmente o contexto atual precipite a concepção de projetos de desenvolvimentos menos homogêneos, e novos paradigmas científicos capazes de incorporar os saberes locais.

Portanto, a sustentabilidade da agricultura precisa estar intimamente ligada com os pressupostos multidimensionais e precisa ser compreendido como tal. As ciências agrárias têm demonstrado dificuldades do ponto de vista metodológico quando se lança em reflexôes multidisciplinares envolvidas nos processos produtivos. O desafio maior é compor ferramentas que ajudem na compreensão da realidade, exigindo, portanto, considerar suas múltiplas dimensões: econômica, ecológica, social, cultural, política, ética etc.

\subsection{A necessidade de novas concepções metodológicas}

Do ponto de vista metodológico, a proliferação de pesquisas exploratórias (Diagnósticos Rápidos e Participativos) e o uso de indicadores propiciarão leituras mais amplas das realidades agrícolas (VAN BELLEN, 2002; COLAÇO-DE-ROSÁRIO e COSTA, 2006; SARANDÓN et. ali., 2006). Entretanto, apesar de produzirem informações multidimensionais, tais ferramentas de coleta e análise nem sempre têm permitido leituras que extrapolem a dimensão técnico-econômica dos processos produtivos.

Neste aspecto, embora exista muita imprecisão acerca do significado do Desenvolvimento Sustentável, dois pressupostos têm sido fundamentais para superar tais limitaçôes: a) o conjunto de processos produtivos não pode mais ser encarado sem suas dimensões sociais e ambientais; b) os novos espaços agrários devem assumir dinâmicas mais compromissadas com a equidade sócio-econômica e, acima de tudo, re-valorizar os conhecimentos construídos historicamente pelas populações locais, transformando tais categorias sociais em principais condutores das mudanças necessárias para um desenvolvimento comprometido com as futuras gerações.

Tais desafios tem sido alvo de recentes reflexões que buscam leituras e avaliações multidimensionais sobre as distintas realidades em que a agricultura familiar brasileira está inserida, especialmente na busca da adaptação de 
Impactos

pronaf

sudeste

paraense:

Avaliação da sustentabilidade de agroecossistemas familiares

ferramentas de avaliação da sustentabilidade, mas de pouca aplicação na escala local (MARZALL, 1999; VAN BELLEN, 2002; BELLEN, 2006, entre outros).

Para Cunha (2003), o uso de sistemas de indicadores emerge justamente da deficiência da academia em dispor de uma leitura mais realista da dinâmica atual de nossas relações para com a natureza. Até a década de 1970 havia pouca preocupação com a qualidade de informações, além da falta de marcos metodológicos capazes de antecipar as atuais crises ambientais.

\section{2. $\mathrm{O}$ uso do MESMIS como ferramenta de avaliação da sus- tentabilidade local}

O Marco de Avaliação de Sistemas de Manejo Incorporando Indicadores de Sustentabilidade (MESMIS) tem sido aplicado como alternativa metodológica de leitura sistêmica do funcionamento de agroecossistemas familiares, detectando aspectos práticos de avaliação de uma sustentabilidade multidimensional (MASERA, ASTIER \& LOPEZ-RIDAURA, 1999; ASTIER et al., 2002; COLAÇO-DE-ROSÁRIO e COSTA, 2006). Sua aplicação tem possibilitado comparações entre agroecossistemas de base ecológica e agroquímica (ALONSO e GUZMÁN, 2006), mas seu foco principal tem sido o desenvolvimento de indicadores capazes de avaliar agroecossistemas complexos (SARANDÓN et al., 2006; ASTIER et al., 2002; COLAÇO-DEROSÁRIO e COSTA, 2006; CORRÊA, 2007; VERONA, 2008).

Para garantir uma avaliação de diferentes sistemas de manejo e escalas (parcelas produtivas, agroecossistema, comunidade), o MESMIS segue as seguintes premissas:

I. a prévia definição de um conceito local de sustentabilidade, através de até cinco atributos (critérios) gerais: produtividade, estabilidade, adaptabilidade, equidade e autodependência (ou Autogestão);

II uma definição clara dos limites espacial e temporal na avaliação. Estes garantem uma maior aproximação com a realidade e, consequentemente, sua restrição à generalização de resultados;

III não se aplica em avaliação per se. Desta forma, ele pode ser aplicado de forma comparativa, seja ela longitudinal (diacrônica) ou transversal (sincrônica); 
IV garante um nível importante de participação dos atores envolvidos no contexto, além de buscar envolvimento com equipes interdisciplinares;

V é um processo cíclico, possibilitando revisão constante da realidade e ou da própria ferramenta.

No tocante à operacionalização do MESMIS (ASTIER et al., 2002), seis passos podem resumir sua aplicação:

$1^{\circ}$ Passo: Determinação do objeto de avaliação. Caracterizar os agroecossistemas, descrevendo seus elementos constitutivos e o contexto envolvente (social, ambiental, económico etc.). Um passo importante é a definição de um sistema de referência, ou seja, que garanta uma representatividade local;

$2^{\circ}$ Passo: Determinação dos pontos críticos. Identificar aspectos limitantes e potencialidades que aparentam afetar a sustentabilidade do agroecossistema, considerando e ponderando os atributos escolhidos para a avaliação. Além disto, se faz necessário determinar critérios de avaliação para cada atributo definido;

$3^{\circ}$ Passo: Seleção de indicadores. A definição de indicadores dependerá diretamente dos critérios definidos de acordo com as limitações e potencialidades detectadas no agroecossistema em questão;

$4^{\circ}$ Passo: Medição e monitoramento dos indicadores. Fase de coleta dos dados a serem utilizados na avaliação da sustentabilidade;

$5^{\circ}$ Passo: Integração dos resultados. São estabelecidas as comparações entre agroecossistemas, indicando os obstáculos e potencialidades para garantir uma sustentabilidade local. A representação gráfica converte-se em alternativa interessante do ponto de vista didático;

$6^{\circ}$ Passo: Conclusões e recomendações. Constrói-se uma síntese da avaliação, podendo derivar em proposições de mudanças nos agroecossistemas e um novo protocolo de avaliação. 
Impactos do pronaf no sudeste paraense: Avaliação da sustentabilidade de agroecossistemas familiares

\section{ASPECTOS METODOLÓGICOS DO ESTUDO}

Dentro do território sudeste do Pará, o recorte empírico do presente estudo é constituido por um Projeto de Assentamento de Reforma Agrária (PA). Optou-se por uma amostra intencional composta por nove agroecossistemas, totalizando $10 \%$ do total de familias residentes no assentamento estudado. $\mathrm{O}$ principal critério estava na opção de ter acessado ou não o crédito produtivo, além de explorarem as áreas por pelo menos cinco ciclos agrícolas.

Foram definidos os índices de avaliação ambiental, social e técnicoeconômica, desdobrados nos indicadores de sustentabilidade (quadro 02).

A descrição do problema e a obtenção das informações foram garantidas através do uso de revisão documental e técnica de coleta de dados via a aplicação de roteiro semi-estruturado, questionário composto por perguntas semi-abertas e observações de campo.

Inicialmente foi sistematizada uma noção local de sustentabilidade

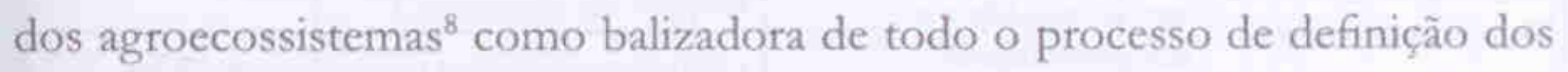
indicadores mais preponderantes no atual contexto dos agroecossistemas estudados, ou seja:

"A sustentabilidade se faz quando a familia se encontra inserida em um contexto favorável para sua fixação e manutençăo da diversidade produtiva; autônoma em relação ao seu consumo e condução dos projetos futuros; e capaz de exercer minimamente a cidadania (SILVA, 2008, p. 87)."

A ferramenta de apoio na definição dos indicadores de análise foi o Marco de Avaliação de Sistemas de Manejo Incorporando Indicadores de Sustentabilidade (MESMIS), por ser flexível do ponto de vista conceitual e permitir uma avaliação multidimensional". A opção foi de priorizar três dimensões consideradas fundamentais: a ambiental, a econômica e a social (ASTIER et al., 2002; COLAÇO-DO-ROSÁRIO e COSTA, 2006 e SARANDÓN et al., 2006).

8 Construída em conjunto com a (s) comunidade(s) protagonistas do presente estudo.

9 Além das três dimensões aqui abordadas, ainda se tem avaliado as dimensỏes politica e cultural dos sistemas estudados. 


\section{Quadro 01: Síntese dos procedimentos metodológicos realizados durante}

\section{o estudo}

\begin{tabular}{|c|c|c|}
\hline Etapas & Procedimentos & Formas de coleta de informaçốes \\
\hline \multirow{5}{*}{$\begin{array}{l}\text { - Definição dos } \\
\text { agroecossistemas } \\
\text { estudados }\end{array}$} & $\begin{array}{l}\text { - Reconhecimento do } \\
\text { contexto regional }\end{array}$ & - Revisão documental. \\
\hline & $\begin{array}{l}\text { - Socialização da proposta } \\
\text { de estudo junto às equipes } \\
\text { de ATER regionais }\end{array}$ & $\begin{array}{l}\text { - Reuniōes com téenicos: Equipe de } \\
\text { Articulaçãao e Cooperativas de Prestação de } \\
\text { serviços (Copserviços). }\end{array}$ \\
\hline & \multirow{3}{*}{$\begin{array}{l}\text { - Recorte espacial da } \\
\text { amostra }\end{array}$} & $\begin{array}{l}\text { - Visita em área selecionada (01 Projeto de } \\
\text { Assentamento); }\end{array}$ \\
\hline & & - Entrevistas com pessoas-chave; \\
\hline & & $\begin{array}{l}\text { - Mapeamento dos agroecossistemas: } 09 \\
\text { agroecossistemas (10\%do Assentamento). }\end{array}$ \\
\hline \multirow[t]{2}{*}{$\begin{array}{l}\text { - Noção da } \\
\text { sustentabilidade local } \\
\text { de agroecossistemas }\end{array}$} & \multirow{2}{*}{$\begin{array}{l}\text { - Construção de um } \\
\text { conceito local de } \\
\text { agroecossistema e } \\
\text { sustentabilidade }\end{array}$} & $\begin{array}{l}\text { - Entrevistas com técnicos e agricultores do } \\
\text { assentamento amostrado e observaçōes de } \\
\text { campo; }\end{array}$ \\
\hline & & - Sistematizaçấo das noções apreendidas. \\
\hline \multirow{11}{*}{$\begin{array}{l}\text { - Avaliaçẫo do } \\
\text { estado atual dos } \\
\text { agroecossistemas }\end{array}$} & \multirow{3}{*}{$\begin{array}{l}\text { - Identificação de limites } \\
\text { e potencialidades dos } \\
\text { agroecossistemas }\end{array}$} & $\begin{array}{l}\text { - Entrevistas e aplicação de questionário } \\
\text { junto às famílias selecionadas; }\end{array}$ \\
\hline & & $\begin{array}{l}\text { - Sistematização do estado atual dos } \\
\text { agroecossistemas; }\end{array}$ \\
\hline & & $\begin{array}{l}\text { - Construção do quadro síntese dos pontos } \\
\text { críticos. }\end{array}$ \\
\hline & \multirow{3}{*}{$\begin{array}{l}\text { - Composição de um } \\
\text { conjunto de critérios para } \\
\text { cada dimensão estudada }\end{array}$} & $\begin{array}{l}\text { - Agrupamentos dos principais problemas } \\
\text { identificados; }\end{array}$ \\
\hline & & $\begin{array}{l}\text { - Construção da grade de indices e } \\
\text { indicadores a serem avaliados; }\end{array}$ \\
\hline & & $\begin{array}{l}\text { - Definição de escalas de valores e } \\
\text { ponderaçôes dos indicadores selecionados. }\end{array}$ \\
\hline & \multirow{5}{*}{$\begin{array}{l}\text { - Avaliação propriamente } \\
\text { dita }\end{array}$} & - Confirmação dos indicadores selecionados; \\
\hline & & $\begin{array}{l}\text { - Complementação das informações dos } \\
\text { agroecossistemas amostrados; }\end{array}$ \\
\hline & & - Observações de campo; \\
\hline & & $\begin{array}{l}\text { - Sistematizaçâo dos dados e construçâo de } \\
\text { representaçôes gráficas. }\end{array}$ \\
\hline & & $\begin{array}{l}\text { - Sistematizaçâo e avaliação da } \\
\text { sustentabilidade no Assentamento } \\
\text { selecionado. }\end{array}$ \\
\hline
\end{tabular}


Impactos do pronaf no sudeste paraense: Avaliação da sustentabilidade de agroecossistemas familiares

Sobre $o$ aspecto da avaliação da sustentabilidade, após a sistematização final (apêndice 1), foram definidos dez indicadores, conforme o quadro abaixo.

Quadro 02: Apresentação dos indicadores de avaliação selecionados

\begin{tabular}{|c|c|c|c|}
\hline Dimensão & Critério & Indicador / Peso & Atributo \\
\hline \multirow{3}{*}{$\begin{array}{c}\text { AMBIENTAL } \\
(3,33 / 10,0)\end{array}$} & \multirow{2}{*}{ Diversidade } & $\operatorname{ADN}(4,0 / 10,0)$ & \multirow{3}{*}{$\begin{array}{l}\text { Estabilidade e } \\
\text { Adaptabilidade }\end{array}$} \\
\hline & & $\operatorname{ADE}(4,0 / 10,0)$ & \\
\hline & Eficiência & $\operatorname{ALM}(2,0 / 10,0)$ & \\
\hline \multirow{3}{*}{$\begin{array}{l}\text { SOCIAL } \\
(3,33 / 10,0)\end{array}$} & Qualidade de vida & $\operatorname{SQV}(6,0 / 10,0)$. & \multirow{3}{*}{ Equidade e Produtividade } \\
\hline & $\begin{array}{l}\text { Capacidade } \\
\text { organizativa }\end{array}$ & SORG $(1,0 / 10,0)$ & \\
\hline & $\begin{array}{l}\text { Capacidade de } \\
\text { trabalho }\end{array}$ & $\operatorname{STRAB}(3,0 / 10,0)$ & \\
\hline \multirow{4}{*}{$\begin{array}{c}\text { TÉCNICO- } \\
\text { ECONÔMICO } \\
(3,33 / 10,0)\end{array}$} & Niver de renda & TECON $(3,0 / 10,0)$ & \multirow{4}{*}{$\begin{array}{c}\text { Produtividade, Equidade } \\
\text { e Estabilidade }\end{array}$} \\
\hline & Endividamento & TEDIV $(1,0 / 10,0)$ & \\
\hline & Eficiência produtiva & TEFIC $(3,0 / 10,0)$ & \\
\hline & $\begin{array}{l}\text { Capacidade de } \\
\text { diversificar }\end{array}$ & TEDIVERS $(3,0 / 10,0)$ & \\
\hline
\end{tabular}

Legenda: ADN (Diversidade Natural); ADE (Diversidade de Espécies cultivadas); ALM (Limitações impostas ao meio); SQV (Qualidade de Vida); SORG (nível de Organização); STRAB (Capacidade de Trabalho); TECON (Performance econômica); TEDIV (Divida); TEFIC (Eficiência produtiva); TEDIVERS (Possibilidades de diversificação).

Em síntese, no processo avaliativo se buscou indicadores que refletissem uma operacionalidade do conceito apreendido localmente, além de garantir um peso equivalente entre as três dimensões privilegiadas no estudo. 


\section{RESULTADOS ALCANÇADOS}

\subsection{Caracterização do contexto que envolve os agroecossiste- mas avaliados}

Localizado no município de Itupiranga, o Projeto de Assentamento La Estância dista aproximadamente $50 \mathrm{~km}$ da sede municipal ${ }^{10}$, com precário acesso terrestre. Sua localização geográfica fica entre a latitude $5^{\circ} 15^{\prime} \mathrm{S}$ e Longitude $49^{\circ} 35^{\prime} \mathrm{W}$, compondo um complexo federal de regularização fundiária em apoio à agricultura familiar. Há bem pouco tempo atrás esta mesma região era conhecida como microrregião de "posseiros" migrantes, com forte dinâmica de fronteira agrícola.

Cabe salientar que a representação espacial ilustrada na figura 01 destaca apenas as áreas regularizadas, existindo ainda grandes propriedades com pecuária extensiva e outros agroecossistemas familiares de ocupações antigas, mas que ainda permanecem fora do processo oficial de regularização fundiária. A pressão das grandes fazendas por pastagens ajuda, em parte, a entender a forte pressão rumo a uma especialização da agricultura familiar regional nesta atividade produtiva que vem transformando drasticamente a paisagem amazônica.

10 Outras distâncias importantes são os $70 \mathrm{~km}$ do assentamento até Marabá (principal pólo de serviços do território sudeste) e os $570 \mathrm{~km}$ até a capital do estado (Belém), ambos os trajetos feitos por rodovias. 
Impactos do pronaf no sudeste paraense: Avaliação da sustentabilidade de agroecossistemas familiares

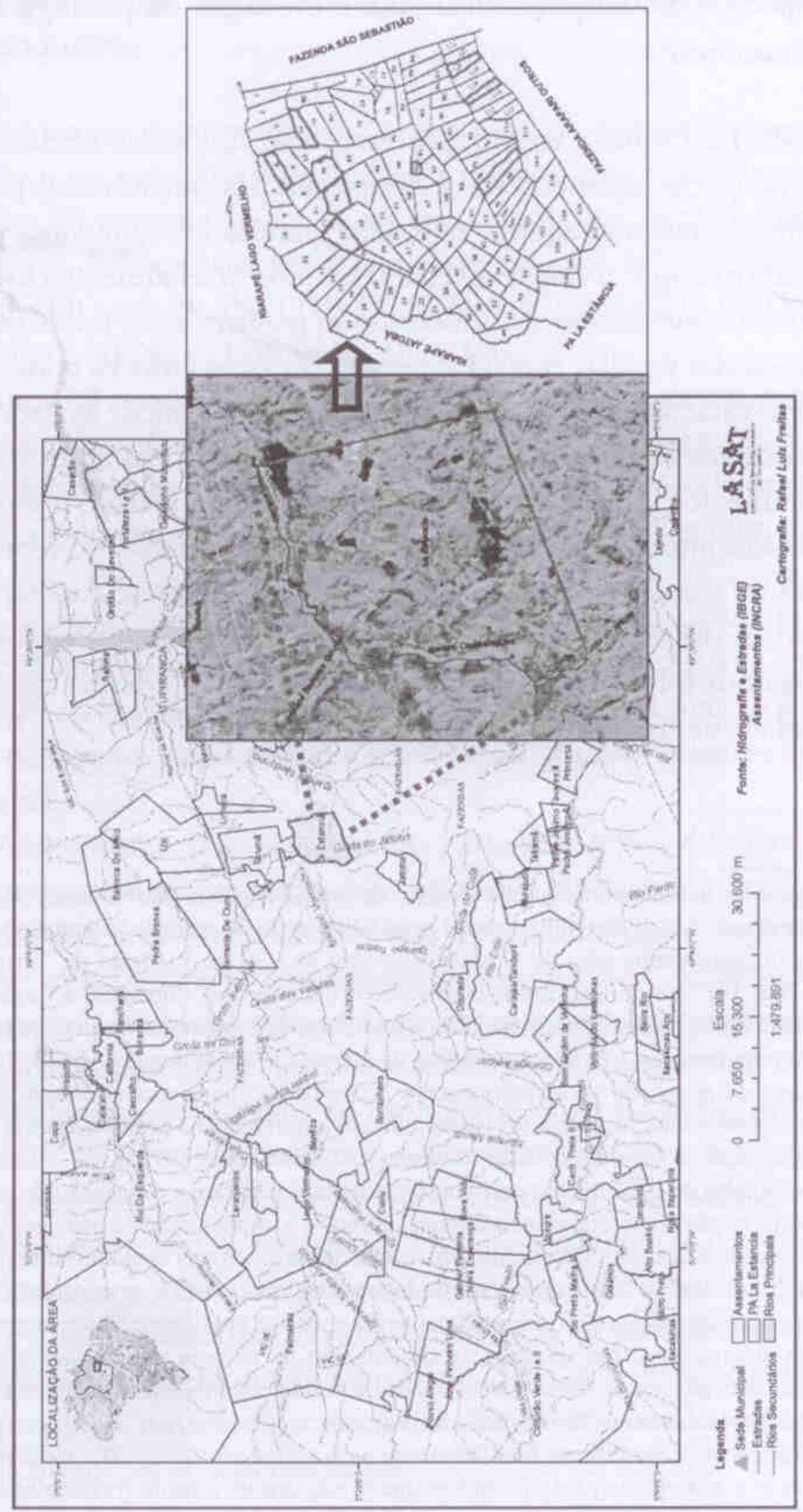




\subsubsection{Aspectos da ocupação humana e evolução da paisagem no as- sentamento}

O PA La Estância entrou nas estatísticas fundiárias oficiais após 14 anos de sua ocupação espontânea. Por decreto, ele passou de área de posse para assentamento de reforma agrária, mas sem grandes investimentos públicos. É possível afirmar que o maior investimento nos assentamentos criados no território ficou concentrado no processo de regularização fundiária, pois a grande maioria das famílias já residia e explorava estas áreas há anos.

Bem característico da frente pioneira amazônica, as três últimas décadas marcaram fortemente o padrāo de ocupação bem antes da criação deste assentamento ${ }^{11}$. Desde o início de sua ocupação humana ${ }^{12}$, o processo de desmatamento e implantação de pastagens cultivadas vem sendo reproduzido.

Mesmo com o aumento considerável da regularização fundiária e certa homogeneidade das estratégias produtivas, a agricultura familiar regional ainda se caracteriza por forte heterogeneidade ${ }^{13}$, mantendo diferenças significativas na possibilidade de fixação desta categoria.

110 atual projeto de assentamento rural é produto de seguidas ocupações de áreas públicas. Inicialmente se deu de forma pouco presencial pela delimitaçăo de grandes fazendas via contratos de aforamento para exploração de Castanha-do-pará através do Instituto de Terras do Pará (ITERPA). Em 1985 culminou com o esgotamento das espécies florestais, a implantação de pastagens cultivadas e conseqüente declinio econômico da família Xavier. A chegada de migrantes sem terra motivou a ocupação pacifica da fazenda já abandonada (ASSIS, 2000). Após quatorze anos de ocupação e estabelecimento de unidades familiares na antiga fazenda La Estância, a regularização fundiária foi garantida com a mudança da política agrária nacional e consequente criação do Projeto de Assentamento La Estância, em 1995.

12 Durante as décadas de 1960 e 70 as politicas federais incentivaram a concessão de terras públicas para a exploração comercial dos castanhais nativos e a implantação de pastagens na região. Como consequência, a exploração madeireira e a pecuária extensiva consumiram praticamente todas as áreas florestadas. Neste mesmo periodo, a agricultura familiar se consolida com o predomínio das familias migrantes, principalmente do nordeste brasileiro. Neste momento, tanto empresários quanto posseiros apostam na substituição da floresta por pastagens cultivadas, como formas de valorização das áreas ocupadas e futuro reconhecimento público (título da terra ou uma venda das áreas "formadas" com capim).

13 Pode-se diferenciar a agricultura familiar desde as famílias sem perspectivas de titulação da terra (posseiros e acampados) até as familias que já adquiriram o título (residentes na beira de rodovia federais ou atingidos pela barragem da Hidrelétrica de Tucurui), mas se encontram sem reservas florestais para a garantia de suas atividades agricolas (VEIGA et. al., 2007). 
4.1.2. Aspectos do meio biofísico que influenciam as atividades produtivas

Conforme já mencionado, o processo de pecuarização se repetiu no entorno e no próprio assentamento. $O$ índice interno de desmatamento nos últimos 18 anos foi de $2,2 \%$ ao ano, sendo que desde a chegada das familias a área do assentamento contava apenas com $50 \%$ de floresta nativa (DIAGNÓSTICO E PLANO DE DESENVOLVIMENTO DO PROJETO DE ASSENTAMENTO LASTÂNCIA, 2004).

Após 22 anos de exploração, ao invés da floresta densa, predominam as pastagens cultivadas e a pecuária tem se afirmado como principal atividade produtiva dificultando a manutenção de outras atividades mais características da agricultura familiar regional onde geralmente predomina a diversificação de atividades.

A rápida conversão da floresta em pastagens acelerou também algumas crises nos agroecossistemas ainda diversificados. Além do risco do uso do fogo no manejo de pastagens, a falta de áreas de vegetação primária (ou areas de pousio) impossibilita a reprodução de cultivos anuais via sistema corte-queima.

Vale ressaltar que as áreas de pastagens têm sido tratadas como cultivos permanentes, especialmente devido à ausência de tecnologias de re-utilização das áreas cultivadas. E esta dificuldade explica, em parte, uma espécie de "mito" sobre a "perenização" da pecuária na Amazônia devido à limitaçào tecnológica das familias em re-incorporar as áreas de pastagem para outras atividades produtivas. Esta limitação acaba apontando um dos maiores dilemas das familias assentadas: a) especialização na pecuária, investindo na concentração de terras e esvaziando o assentamento; b) nova migração em busca de novas áreas com floresta, mais distantes e de pior acesso.

Atualmente com o acesso de linhas oficiais de crédito, outra opção tem sido investir na moto-mecanização como alternativa de retorno nas áreas de pasto e intensificação das atividades agrícolas. $O$ problema na adoção da mecanização se concentra no alto custo e na falta de experiência das familias, além de precipitar novos impactos sobre os recursos naturais (ex. processos erosivos já presentes no assentamento). 
Sobre os recursos hídricos, são raros os depoimentos de limitações, pois Itupiranga é um município entrecortado por inúmeros rios e igarapés. $\mathrm{O}$ assentamento La Estância apresenta mais impedimentos relacionados ao seu excesso (áreas de baixada ou próxima aos leitos de rios) do que sua escassez sazonal. Mesmo com uma sensível redução da frequência pluviométrica histórica deste território, não se relata situação local de limitação hídrica grave durante a execução dos calendários agrícolas.

No tocante as características pedológicas, mesmo com ausência de pesquisas específicas sobre este tema, o assentamento apresenta uma grande heterogeneidade. O material geológico mais encontrado é à base de Xistos, com destaque para os Podzols Vermelho Amarelo com textura argilosa e com forte presença de Plintitas ou nódulos ferruginosos decorrente dos períodos de saturação hídrica. A circulação de água é mais intensa no sentido horizontal, beneficiando o cultivo antecipado de arroz sem grandes comprometimentos por eventual déficit hídrico no início das chuvas. As características estruturais e químicas deste solo $^{14}$, somadas a sua moderada fertilidade natural, contribuem para a produção do arroz - consumo e abastecimento local - mas limitam o cultivo de tubérculos (mandioca).

\subsubsection{Aspectos sociais do assentamento}

A pouca presença do Estado contribui ainda mais para as limitadas perspectivas de melhoria de vida das familias assentadas. Desde o início de sua ocupação, a infra-estrutura interna do assentamento pouco evoluiu. Antes do assentamento, a ligação das famílias com o mundo exterior estava diretamente vinculada à intervenção de madeireiros na abertura de estradas internas (venda de árvores de valor comercial) e com pecuaristas na inserção do mercado da carne. As poucas conquistas sociais (escola de ensino fundamental e agente de saúde) tiveram participação direta do movimento sindical.

Após 15 anos de criação do assentamento, muito da fragilidade das políticas sociais se justifica pela total falta de articulação entre as políticas de reforma agrária e o poder público municipal e estadual.

14 Os Xistos, tendo as Micas como essencial constituinte mineral, contribui com representativas fontes de Potássio e Magnésio, proporcionando condiçôes para o desenvolvimento de determinados cultivos que demanda fortemente destes elementos (cupuaçu, cacau, banana, entre outros) (DOSSO et. al., 1999). 
Impactos do pronaf no sudeste paraense: Avaliação da sustentabilidade de agroecossistemas familiares

O baixo investimento público nos serviços de educação fica patente quando se compara os percentuais da escolaridade do assentamento. $O$ analfabetismo está presente em $11 \%$ dos assentados e mesmo com o amplo acesso ao Programa Bolsa Familiaa ${ }^{15}$, cerca de $60 \%$ estudaram apenas até a $4^{a}$ série do ensino fundamental. Com apenas três escolas de ensino fundamental incompleto, fica difícil o assentamento dispor de um contexto educacional mais favorável.

No caso dos serviços de saúde, a situação é mais drástica ainda. Não existem postos de saúde e a atuação do único agente de saúde do assentamento está limitada a esporádicas vistorias epidemiológicas ${ }^{16}$. Desta forma, as familias são obrigadas a empreender seus limitados recursos financeiros na busca destes serviços nos centros urbanos.

Sobre o tema lazer, inexiste infra-estrutura comunitária e de organização recreativa no local. São raros os momentos de festividades coletivas e os encontros se limitam às reuniões e atividades religiosas $(73 \%$ das familias são evangélicas e $27 \%$ católicas).

Além da deficiência das escolas e ausência total de saneamento básico e saúde, o baixo investimento público se confirma na precariedade das estradas vicinais; na falta de eletrificação para o conforto familiar, conservação e beneficiamento de produtos e; na ausência de serviços de telefonia.

No início da ocupação da área, a localidade vivenciou um periodo de forte representação política, através da criação de delegacias sindicais e reivindicação da posse da terra. Com a criação do assentamento, a associação dos assentados assumiu mais um caráter de exigência legal, para acessar o crédito produtivo.

\subsubsection{Os agroecossistemas familiares predominantes}

Os agroecossistemas familiares deste território ainda guardam significativa diversidade em suas atividades produtivas e uma base tecnológica

15 O Programa Bolsa Familia (PBF) é um programa de bem-estar social desenvolvido pelo governo federal brasileiro em 2003 para integrar o Programa Fome Zero. Consiste na ajuda financeira às famílias pobres e indigentes do país, com a condição de que estas mantenham seus filhos na escola e vacinados. O programa visa reduzir a pobreza a curto e em longo prazo através de transferências condicionadas de capital, o que, por sua vez, visa acabar com a transmissão da miséria de geração a geração (MDS, 2008).

16 As doenças mais freqũentes são: parasitoses intestinais, malária, dengue e alguns casos de hepatite e hanseníase. 
de baixo investimento em insumos externos ${ }^{17}$. Veiga et al. (2007) confirmam a predominância do sistema de corte-queima tanto na fase de preparo como na limpeza das parcelas produtivas (grāos e forragens). A maior novidade fica por conta da introdução, mesmo que tímida, de parcelas com espécies frutíferas e atividades de piscicultura.

Estudos anteriores à criação do assentamento (VEIGA, 1999; ASSIS, 2000) descrevem alguns aspectos importantes dos agroecossistemas antes da intervenção sistemática ligada ao Pronaf. As principais atividades produtivas nesta época pouco mudaram nos dias atuais, excetuando a redução das áreas de cultivos anuais (arroz, milho, feijão e mandioca) devido principalmente a pouca disponibilidade de áreas de mata e capociras.

Segundo o diagnóstico realizado recentemente pela equipe técnica local, (DIAGNÓSTICO E PLANO..., 2004), de forma sintética, dois grandes grupos de agroecossistemas estão presentes:

I Familias sem gado: agroecossistemas baseados em sistema de corte-queima para cultivos anuais de grãos e posterior implantação de pastagens. A renda de pequenos animais e da mão-de-obra complementava a renda, e o património familiar médio era menor que RS $5.000,00$. Em alguns casos, o início da pecuária se dava via aluguel de pastagens.

II Familias com gado: agroecossistemas em franca especialização na pecuária extensiva, com início do rebanho próprio. As atividades agricolas e de pequenas criações perdiam importância, assim como a venda de mão-de-obra. Com um patrimônio superior (maior que R\$ $10.000,00)$, a maior dificuldade estava no limite físico de implantação das pastagens, obrigando as famílias a adquirir mais área florestada ou vender o lote e buscar lotes maiores. (fonte: adaptado do DIAGNÓSTICO E PLANO..., 2004).

O processo de pecuarização tem contribuido negativamente na manutenção da diversidade natural, pois homogeneíza a paisagem através do estabelecimento de monocultivos de pastagens cultivadas, reduzindo as áreas de cultivos anuais e perenes, especialmente devido o alto custo do processo técnico de substituição das atuais pastagens por cultivos alimentares.

17 Devido os altos custos e total falta de experiência, o uso de insumos químicos ainda não é rotineiro nos agroecossistemas familiares da região. 
Impactos

do

pronat

no sudeste

paraense:

Avaliaçao da sustentabilidade de agroecossistemas familiares

Com o fim das áreas de mata e capoeira, a impossibilidade da implantação de roças de consumo e o sobrepastejo ${ }^{18}$ apontam para uma crise técnica nos agroecossistemas.

Em termos de experiências locais, Veiga (1999) e Assis (2000) citam algumas alternativas de diversificação que se apresentavam bem adaptadas às condições locais, mas foram esquecidas ou pouco valorizadas pela intervenção técnica. O cultivo de urucum (Bixa orellana L.), cultivo do feijão "abafado" (Vignia unguiculata L.) e, cultivo de roça em áreas próximas ao leito de rios.

\subsubsection{O Pronaf e a manutenção da pecuária como atividade prioritária}

Fazendo uma breve leitura no Plano de Desenvolvimento do Assentamento (PDA) realizado no assentamento (DIAGNÓSTICO E PLANO..., 2004), não é dificil perceber a dificuldade que os técnicos demonstram em articular o conhecimento técnico com a realidade. Poucos elementos dos agroecossistemas predominantes são valorizados na etapa de definições das ações prioritárias. $\mathrm{Na}$ verdade, a maioria das atividades produtivas sugeridas para financiamento é exógena às famílias ou ainda estão limitadas às convicções profissionais dos próprios técnicos responsáveis pelo acompanhamento do assentamento. Mesmo com a possibilidade de reverter à dinâmica de fronteira, a pecuária bovina ainda predomina nas propostas submetidas junto às agências bancárias.

\subsection{Avaliação da sustentabilidade dos agroecossistemas de La Estância}

O significado de sustentabilidade que norteia esta avaliação, conforme mencionado anteriormente é aquele construído junto aos atores locais.

"Unidade familiar inserida em um contexto favorável para sua fixação e manutenção da diversidade produtiva; autônoma em relação ao seu consumo e conduçâo dos projetos futuros; e capaz de exercer minimamente a cidadania."

18 Na região, o sobrepastejo se caracteriza quando a lotação animal ultrapassa $01 \mathrm{UA} / \mathrm{Ha}$. Ainda segundo Veiga et al. (2004), o manejo extensivo adotado na região suporta entre 0,5 a 1,0 UA/ha.

Agr. Fam. Belém n 9 p. $39-802009$ 
O contexto favorável explicita a necessidade de um entorno minimamente favorável às familias. Quanto mais favoráveis às condições do município e território, maiores as possibilidades dos assentamentos acessarem políticas de apoio produtivo e os serviços sociais.

O processo de fixação familiar se expressa inicialmente na garantia da posse legal da terra. A manutenção da diversidade produtiva é apontada como fundamental para a garantia de perenidades dos agroecossistemas familiares desta região, especialmente a autonomia no consumo familiar. Autonomia na implementação de seus projetos futuros também é decidir aonde investir nos projetos familiares.

Para abordar o real sentido do exercício da cidadania, é fundamental o reconhecimento social dos agroecossistemas familiares, considerando principalmente serviços essenciais como: saúde, educação e algumas infraestruturas básicas. Além disto, conta muito uma participação ativa nas decisões coletivas (SEN, 2000).

A sustentabilidade atual dos agroecossistemas avaliados no $\mathrm{PA} \mathrm{La}$ Estância se encontra em niveis bastante preocupantes (figura 02). A maioria dos agroecossistemas se mantém abaixo da linha crítica. Quando observados os valores de cada dimensão avaliada, percebe-se que dificilmente os agroecossistemas alcançam valores próximos do ideal (nota 3,0), confirmando que a fragilidade da sustentabilidade aparece em todas as dimensões.

Nos agroecossistemas que acessaram o crédito, a gravidade está na drástica redução de seus recursos naturais, principalmente na aceleração do plantio de pastagens. Enquanto que nos demais agroecossistemas a dimensão ambiental apresenta valores menos críticos e mais dificuldades na baixa capacidade de investimento nas atividades produtivas e na melhoria da qualidade de vida dentro do assentamento. 


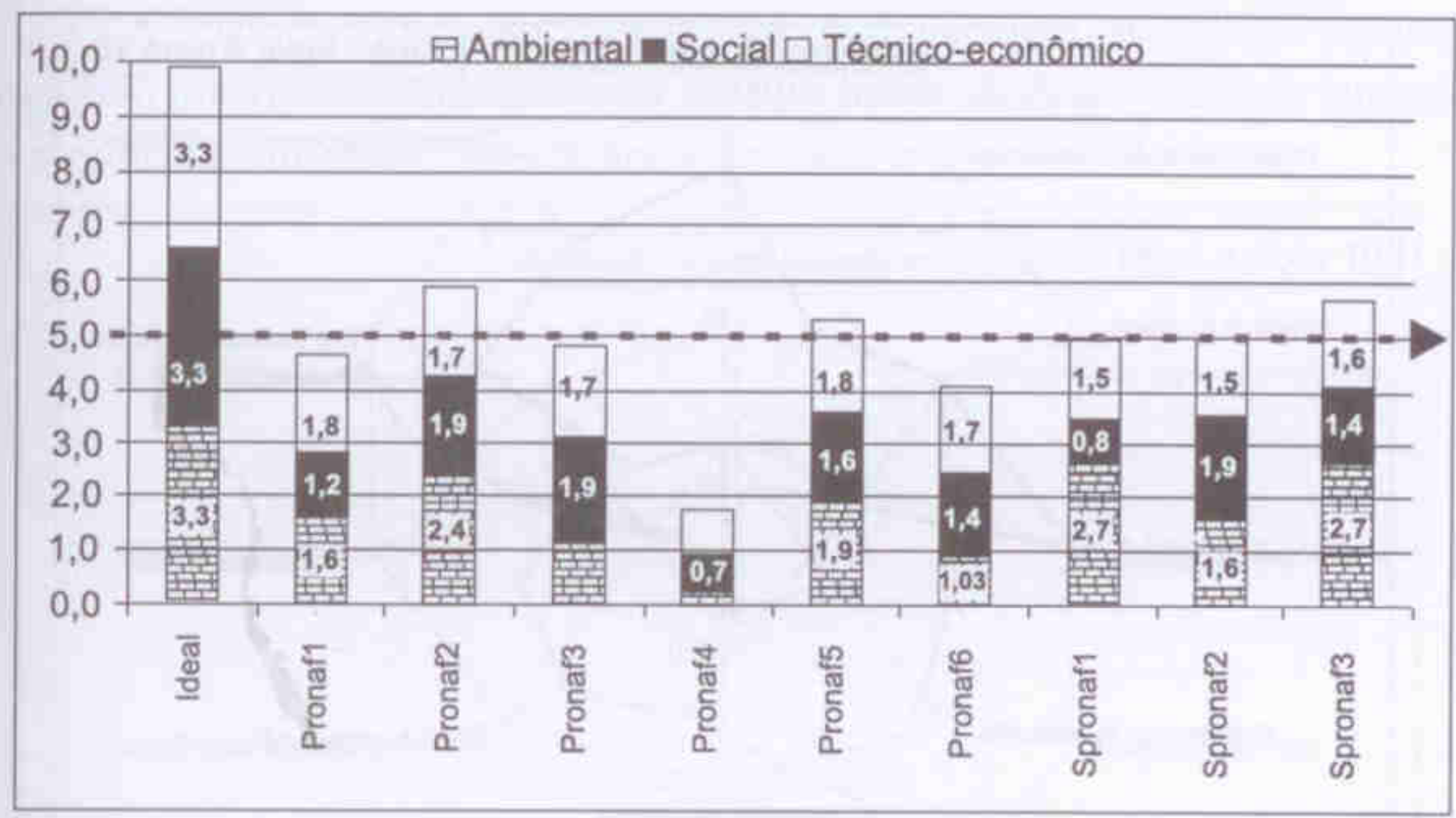

Figura 02: Síntese geral dos níveis de sustentabilidade dos agroecossistemas amostrados na La Estância, Itupiranga. Fonte: Silva (2008).

Legenda: Pronafn = agroecossistemas que acessaram o crédito;

SPronafn $=$ agroecossistemas que não acessaram o crédito).

\subsubsection{Sobre a dimensão ambiental:}

Considerando a amostra e o contexto do assentamento, os agroecossistemas que acessaram o Pronaf " $\mathrm{A}$ "19 demonstram maior proximidade de uma crise técnica pela reduzida biodiversidade (quase $100 \%$ do lote em pastagem), enquanto que as famílias que ainda não acessaram o crédito apresentam ainda representativas áreas de mata e pousio (cerca de 60\%). Os agroecossistemas com maior diversidade natural apontam forte intenção de diversificar as atividades agrícolas e não ampliar as áreas de pastagens. Contudo, muitos não contam ainda com a possibilidade das linhas de crédito devido à falta de flexibilidade que garantam projetos de diversificação agrícola (Figura 04).

190 Pronaf A é a primeira modalidade acessada por uma familia assentada que possui renda bruta de até R\$ 2 mil; sendo até $35 \%$ do valor financiado passivel de ser utilizado em atividades de custeio. 


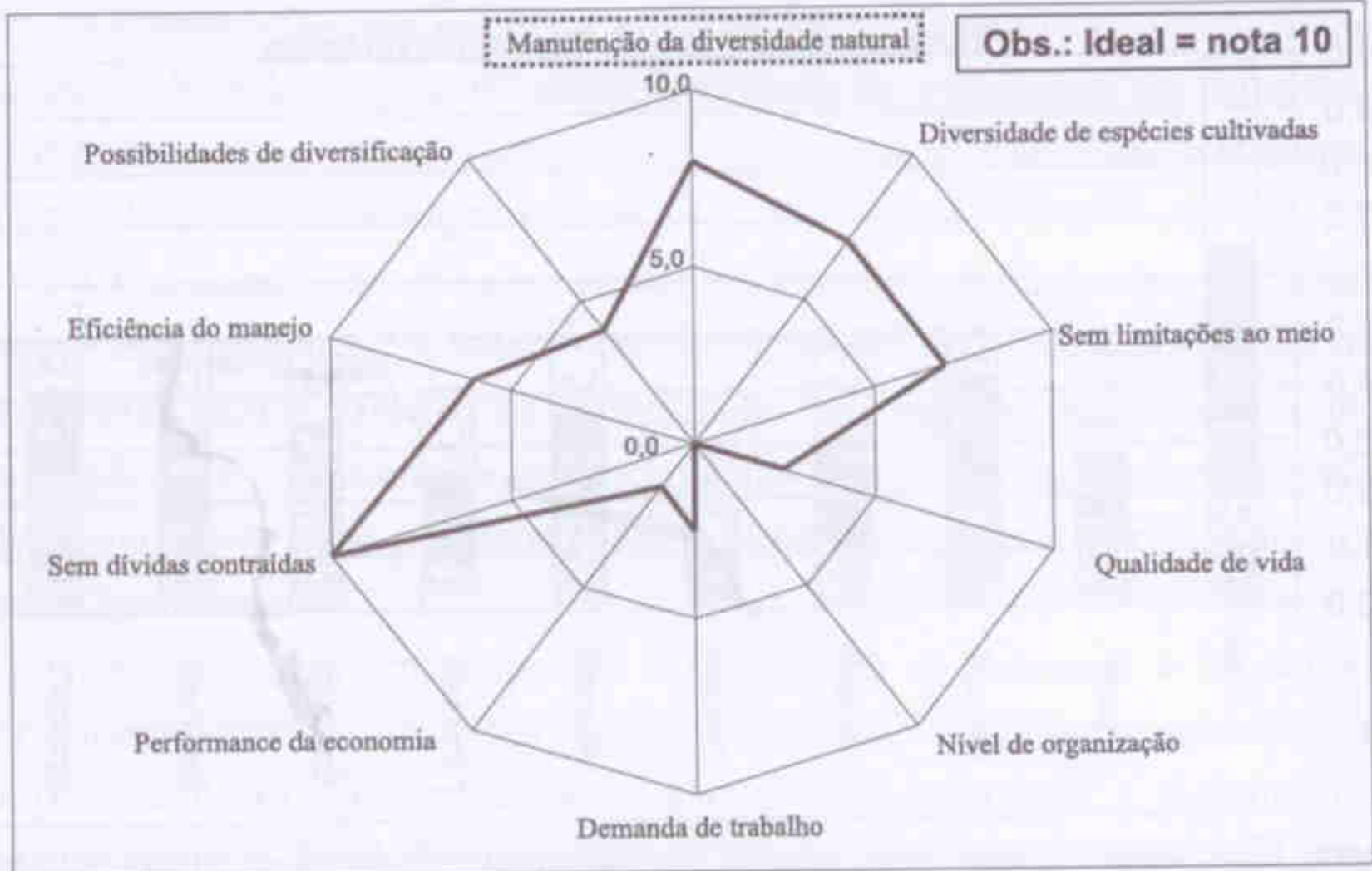

Figura 04: Representação do agroecossistema que não acessou o crédito produtivo (Agroecossistema SPronaf 1). Fonte: Silva (2008).

Atualmente, todas as propostas de crédito estão vinculadas ao investimento na pecuária bovina. Um dos argumentos freqüentes para esta exigência é a baixa capacidade de pagamento das atividades diversificadas (baixa Taxa Interna de Retorno - TIR), estando no gado à garantia do retorno do empréstimo efetuado.

A barreira do aval financeiro erguida pelas agências financeiras (a TIR) parece intransponivel para as equipes técnicas, inibindo a criatividade dos ato res locais.

Contudo, o discurso de que "... O gado éo único que paga o crédito..." pouco a pouco vai sendo superado, mas ainda tem justificado o não atendimento da diversidade de atividades produtivas apontadas pelas famílias assentadas e presentes nos agroecossistemas locais.

O Pronaf parece ainda ter relação direta na continuidade da redução da diversidade natural dos agroecossistemas (figura .05) e a pouca valorização de experiências produtivas presentes e mais adaptadas às realidades destes agroecossistemas familiares. $O$ cultivo do urucum e roças de verão são experiências adaptadas pelas familias, mas pouco valorizadas pela pesquisa e assessoria técnica. 
A maioria dos agroecossistemas que decidem acessar o crédito produtivo invariavelmente apresenta um alto índice de desmatamento interno ou mesmo não dispõem mais de áreas de mata.

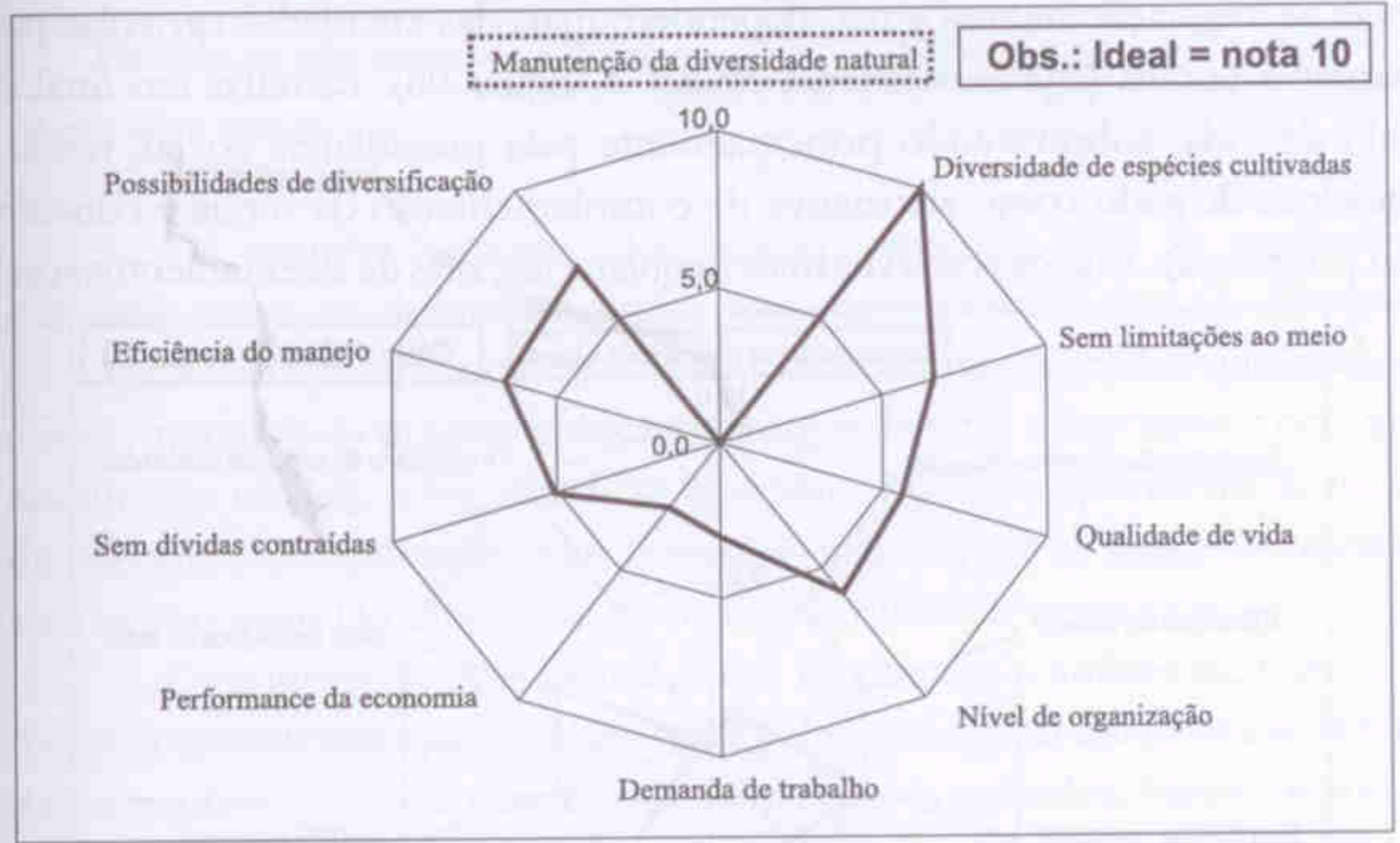

Figura 05: Representação do agroecossistema que acessou o crédito produtivo (Agroecossistema Pronaf 5). Fonte: Silva (2008).

Quadro 03: Manutenção da diversidade natural nos agroecossistemas

\begin{tabular}{|l|c|c|}
\hline \multicolumn{1}{|c|}{ Agroecossistemas } & Manutenção alta & Manutenção baixa \\
\hline Famílias que acessaram o Pronaf & $0 \%$ & $100 \%$ \\
\hline Famílias que não acessaram o Pronaf & $66 \%$ & $34 \%$ \\
\hline
\end{tabular}

Fonte: Silva (2008).

A alta diversidade de espécies e das atividades produtivas denuncia uma forte característica da agricultura familiar regional: manter agroecossistemas diversificados.

O potencial contido nas estratégias ancestrais de manutenção do consumo familiar, explicam uma das formas mais comuns de intensificação do uso de áreas incorporadas pelas atividades agrícolas. A noção de intensificação local não passa necessariamente pelo investimento em tecnologias onerosas. 
As familias compensam a redução de suas áreas agrícolas intensificando o ciclo agrícola e, ao mesmo tempo, elevando a demanda de trabalho familiar.

Uma das exceções reside nos agroecossistemas que esgotaram suas áreas de vegetação natural e não dependem mais das atividades agrícolas para manter a família (agroecossistema Pronaf 4, figura 06). Familias em final do ciclo de vida, sobrevivendo principalmente pela previdência social, tendo a aquisição de gado como alternativa de complementação da renda e consumo (ou poupança). Situação cada vez mais freqüente nas vilas de assentamentos rurais.

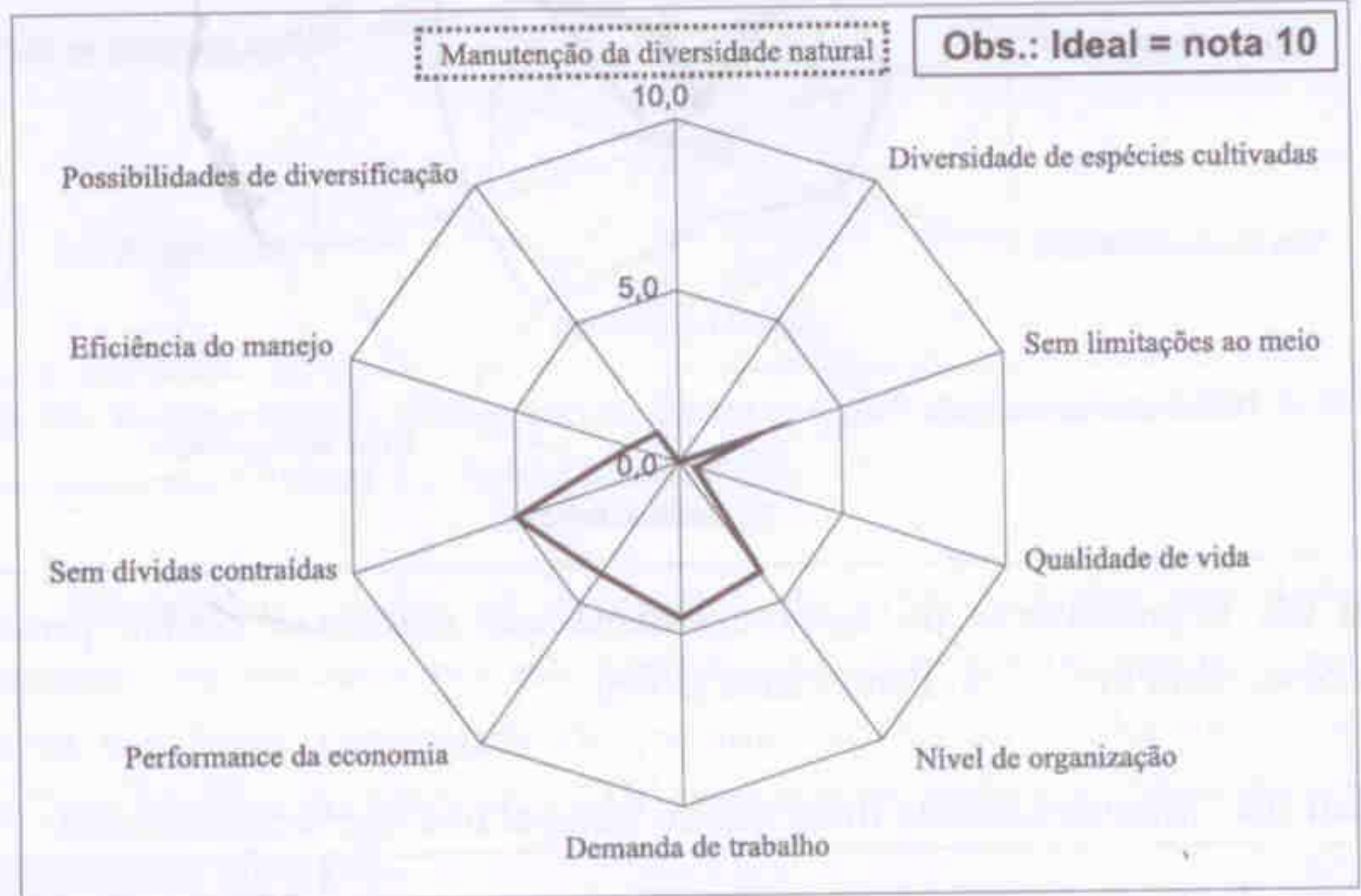

Figura 06: Representação do agroecossistema Pronaf 4. Fonte: Silva (2008).

Nos agroecossistemas com maior diversidade natural, as familias consideram que o investimento na ampliação da diversidade das atividades produtivas é fundamental para garantir a permanência no assentamento. A demanda por espécies frutíferas tem aumentado significativamente devido a perspectiva de melhoria na infra-estrutura regional (estradas, energia elétrica etc.) e a perspectiva de valorização regional das frutas amazônicas. Neste caso, o Pronaf não tem conseguido garantir recursos específicos para investimentos na fruticultura regional e, consequentemente, não avançou na ampliação da diversificação nos agroecossistemas familiares beneficiários diretos destas políticas. 
Quadro 04: Diversidade de espécies cultivadas nos agroecossistemas

\begin{tabular}{|c|c|c|}
\hline Agroecossistemas & Diversidade alta & Diversidade baixa \\
\hline Familias que acessaram o Pronaf & $\mathbf{8 3} \%$ & $17 \%$ \\
\hline Famílias que não acessaram o Pronaf & $100 \%$ & $0 \%$ \\
\hline
\end{tabular}

Fonte: Silva (2008).

Os grandes entraves dos agroecossistemas têm se concentrado nas altas taxas de desmatamento e nas consequêencias do uso sistemático do fogo como prática agrícola. Apesar da atual redução das queimadas no assentamento (pela própria redução das áreas de mata e capoeiras e pela major fiscalização oficial), o fogo ainda se mantém como principal forma de limpeza de pastagens estabelecidas, pois é menos oneroso que as limpezas manuais e até mesmo quando comparado ao uso de herbicidas comerciais.

Considerando uma leitura global da dimensão ambiental, nota-se que os agroecossistemas que acessaram o crédito produtivo apresentam os piores desempenhos quando comparados os indicadores avaliados. Mesmo mantendo uma significativa diversidade nas atividades produtivas, estas familias já apresentam forte crise ecológica, pois tanto o nível de desmatamento quanto a introdução de insumos químicos indicam o comprometimento ecológico do ambiente explorado.

\subsubsection{Sobre a dimensão social}

Excetuando a melhoria de algumas habitações, a atual política de reforma agrária não tem impactado significativamente na qualidade de vida dos assentados. $\mathrm{O}$ assentamento ainda aguarda por outros investimentos como melhoria das infra-estruturas internas (estradas, escolas, eletrificação rural etc.) e serviços ligados à saúde e educação.

Recentemente a qualidade de vida tem sido influenciada positivamente apenas pelo acesso ao Programa Bolsa Familia (PBF), política pública de caráter de inclusão social imediata. Além da garantia de permanência das crianças nas escolas, os recursos do PBF têm propiciado uma importante complementação da alimentação de familias com rendas abaixo de 0,5 salários mínimos per capita/ mês. 
A capacidade de trabalho, maior fator de investimento dos agroecossistemas familiares, está relacionada diretamente com a saúde doméstica. Porém, a maioria das famílias não possui o mínimo de investimento preventivo para a saúde familiar. O lixo doméstico ainda não é encarado como um problema ambiental e continua sendo queimado sem nenhum processo seletivo para incorporação ou reciclagem. A grande novidade na última década tem sido à busca de melhoria do consumo de água familiar, através de filtragem simples e desinfecção artesanal ${ }^{20}$. Esta preocupação está diretamente relacionada com a progressiva redução da quantidade e qualidade da água para consumo domiciliar e acesso a informações básicas de saúde familiar devido às grandes epidemias divulgadas pelos meios de comunicação.

Considerando suas condições habilitadoras (SEN, 2000), as famílias assentadas apresentam uma alta precariedade local, não compreendendo assim perspectivas concretas de um real exercício de cidadania.

Quadro 05: Indicadores ligados às condições habilitadoras dos assentados.

\begin{tabular}{|l|l|l|}
\hline Itens de investimento público & Com Pronaf & Sem Pronaf \\
\hline Serviços de saúde & Sem investimentos & Sem investimentos \\
\hline Serviços de Saneamento básico & Sem investimentos & Sem investimentos \\
\hline Serviços de Educação & Sem investimentos & Sem investimentos \\
\hline Incentivos em treinamentos & Raros & Raros \\
\hline
\end{tabular}

Fonte: Silva (2008).

Para compensar a carência de investimentos em políticas sociais, as familias assentadas acabam dedicando partes de seus rendimentos anuais na manutenção de um patamar mínimo de qualidade de vida. Dentre os agroecossistemas avaliados, ficou evidente a maior capacidade financeira das famílias que acessam o crédito oficial, explicando em partes que a capacidade econômica familiar pode ser decisiva para decidir em acessar ou não acessar os empréstimos produtivos.

20 As técnicas mais utilizadas são: filtragem e desinfecção. Uma operação importante nesses filtros é a da limpeza, na qual é tradicional o emprego de material abrasivo, como o sal e o açúcar. Esta operação não é suficiente para garantir a qualidade da água sem nenhum tratamento prévio. Já a desinfecção via um agente branqueador nas lixivias comerciais é o hipoclorito de sódio, o qual é produzido pela reação do cloro com o hidróxido de sódio. Em solução aquosa, o hipoclorito de sódio dissocia-se em íon sódio e em ion hipoclorito, promovendo, em baixas concentrações, a desinfecção da água. 
Impactos do pronaf no sudeste paraense: Avaliação da sustentabilidade de agroecossistemas familiares

Quadro 06: Gastos médios per capita/mês com qualidade de vida a cada ano

\begin{tabular}{|l|c|c|}
\hline \multicolumn{1}{|c|}{ Itens } & $\begin{array}{c}\text { Familias com } \\
\text { Pronaf }\end{array}$ & $\begin{array}{c}\text { Familias sem } \\
\text { Pronaf }\end{array}$ \\
\hline Gastos médios com Saúde & $\mathbf{R} \$ 22,00$ & $\mathrm{R} \$ 7,50$ \\
\hline Gastos médios com Educaçâo* & $\mathbf{R} \$ 1,00$ & $\mathbf{R} \$ 1,00$ \\
\hline Gastos médios com Organizações Formais & $\mathbf{R} \$ 1,16$ & $\mathrm{R} \$ 1,00$ \\
\hline $\begin{array}{l}\text { Gastos médios na complementação alimentar e } \\
\text { vestuário. }\end{array}$ & $\mathbf{R} \$ 41,60$ & $\mathrm{R} \$ 31,60$ \\
\hline
\end{tabular}

Fonte: Silva (2008). (* prevalecem os recursos do Programa Bolsa Familia).

Em termos gerais, a dimensão social denuncia que a sustentabilidade ainda depende de melhorias significativas no acesso à cidadania dentro dos assentamentos rurais do território sudeste do Pará. E a escassez de serviços públicos não é um problema apenas da zona rural, mas assume contornos dramáticos quando se avalia as ofertas nas sedes administrativas do território.

Com a falta de investimento nestes serviços públicos, as capacidades econômicas das familias assentadas ficam mais fragilizadas devido à obrigação de assumirem gastos que são responsabilidades do poder público e estão previstos na constituição (por ex. direito ao acesso gratuito de serviços de saúde, educação e saneamento básico).

\subsubsection{Dimensão técnico-econômica}

Em termos de desempenho econômico, a maioria dos agroecossistemas amostrados, acessando ou não o crédito produtivo, mantém ainda uma situação bastante crítica. Considerando o limite inferior de 0,5 salários mínimos per capita/mês como referência (KAGEYAMA, 2003), a maioria dos casos observados não supera tal limite. Raros sãos os casos que a renda pode ser considerada razoável. 
Quadro 07: Renda familiar per capita (salário mínimo/mês) nos agroecossistemas

\begin{tabular}{|l|c|c|}
\hline \multicolumn{1}{|c|}{ Agroecossistemas } & Alto & Baixo \\
\hline Familias que acessaram o Pronaf & $17 \%$ & $83 \%$ \\
\hline Familias que não acessaram o Pronaf & $0 \%$ & $100 \%$ \\
\hline
\end{tabular}

Fonte: Silva (2008).

Para agravar a situação, os benefícios trazidos pelas atuais políticas sociais denunciam outra realidade preocupante: a redução progressiva da participação da renda agricola na composição das rendas totais. Mesmo sabendo que ainda seja cedo para se perceber uma influência do crédito produtivo nas rendas familiares, em quase $80 \%$ das familias amostradas, a renda agrícola representa menos de $50 \%$ da renda familiar, estando nos ingressos previdenciários e a venda de trabalho os principais incrementos anuais.

Quadro 08: Comparativo de indicadores ligados à renda familiar de agroecossistemas.

\begin{tabular}{|l|c|c|}
\hline \multicolumn{1}{|c|}{ Médias } & Com Pronaf & Sem Pronaf \\
\hline Renda per capita (salário mínimo/més) & 0,28 & 0,17 \\
\hline Renda Agropecuária (anual) & R\$ 2.332,00 & R\$ 5.975,00 \\
\hline Renda Familiar (anual) & R\$ 5.080,00 & R\$ 4.855,00 \\
\hline Peso da Renda Agropecuária sobre as Rendas Totais $(\%)$ & $31 \%$ & $60 \%$ \\
\hline
\end{tabular}

Fonte: Silva (2008).

Como são investimentos de médio e longo prazo, os impactos mais visiveis estão ainda relacionados com a necessidade de pagamento das parcelas, após o período de carência. Outra diferença marcante com o crédito é a drástica redução na venda de trabalho familiar, devido o aumento expressivo das atividades ligadas ao financiamento produtivo. 
Impactos

Em relação ao patrimônio familiar, o grande peso do valor da terra sobre o valor total demonstra outra fragilidade dos patrimônios construídos até então nos agroecossistemas que não acessaram linhas de crédito produtivo. Podemos supor que os agroecossistemas que acessaram linhas de investimento conseguiram um aumento efetivo de seu património.

Quadro 09: Comparativo de indicadores ligados à renda familiar de agroecossistemas.

\begin{tabular}{|l|c|c|}
\hline \multicolumn{1}{|c|}{ Agroecossistemas } & Com Pronaf & Sem Pronaf \\
\hline Patrimônio familiar & R\$ $50.000,00$ & $25.000,00$ \\
\hline Peso do Valor da terra sobre o patrimônio familiar & $46 \%$ & $\mathbf{7 5} \%$ \\
\hline
\end{tabular}

Fonte: Silva (2008),

Observando de outro ângulo, a política de regularização fundiária contribuiu significativamente para uma maior segurança familiar, além propiciar oportunidade legal da permanência das famílias, rompendo com a necessidade de estratégia migratórias dos agroecossistemas.

Em termos de capacidade de trabalho, as necessidades ligadas ao trabalho familiar ainda são resolvidas internamente (no assentamento). Tanto nos casos de contratação quanto nos de venda de mão-de-obra são resolvidos entre as familias assentadas ou, no máximo, envolvendo familias do entorno dos limites do assentamento.

Em certa medida, o acesso ao crédito oficial tem reduzido à necessidade de venda de trabalho familiar, pois aumenta a demanda interna e, em alguns casos, possibilita a contratação de mão-de-obra para as atividades mais intensivas. O maior aumento parece se concentrar nas atividades ligadas à implantação e manutenção das pastagens, atividades estas que concorrem diretamente com as demais atividades produtivas (em área e em trabalho familiar). Como não se acessa recursos para pagamento de mão-de-obra, esta influência assume um caráter indireto e, portanto, como menor visibilidade local. 
Luis Mauro Santos Silva e Sérgio Roberto Martins

Quadro 10: Capacidade interna de desenvolver as atividades produtivas

\begin{tabular}{|l|c|c|}
\hline \multicolumn{1}{|c|}{ Agroecossistemas } & Com Pronaf & Sem Pronaf \\
\hline Capacidade de trabalho da familia & Baixa & Baixa \\
\hline Venda de mão-de-obra & Baixa & Média \\
\hline Contratação de mão-de-obra & Média & Baixa \\
\hline
\end{tabular}

Fonte: Silva (2008).

A venda de trabalho se concentra principalmente no periodo chuvoso (roço de pastagens e colheitas) e, já em menor intensidade, no verão com o preparo das reduzidas áreas de roçado. Já a oferta de trabalho tem se concentrado mais no verão devido a menor concentração de atividades produtivas, como a época de preparo dos cultivos anuais (derruba e queima da floresta). A maioria das familias está no limite da sua capacidade de trabalho, tendo que tomar decisões importantes como: a) vender mão-de-obra como forma rápida de garantir o consumo familiar. Isto ocorre mais frequentemente devido os casos críticos de ausência ou redução do roçado. b) contratar mão-de-obra vizinha para realizar tarefas em parcelas maiores (limpeza de grandes áreas de pasto). Neste caso, as famílias com rendas maiores acabam estabelecendo relações complementares com as familias menos providas em termos econômicos.

\section{a) Sobre a atual eficiência do manejo do agroecossistema}

Mesmo com a predominância de monocultivos de pastagens na paisagem regional, a diversificação de atividades produtivas ainda predomina na maioria dos agroecossistemas familiares. No caso dos cultivos anuais, a manutenção de uma alta diversidade interna assume grande importância na manutenção da diversidade genética e de práticas, além de garantir o consumo doméstico e justificar o sentimento de ser agricultor: "...o agricultor é o que faz. raça..." (frase de um assentado) 
Impactos do pronaf no sudeste paraense: Avaliação da sustentabilidade de agroecossistemas familiares

Quadro 11: Nivel de diversidade em roças temporárias

\begin{tabular}{|c|c|c|}
\hline Agroecossistemas & Mais de 4 espécies & Menos de 4 espécies \\
\hline Familias que acessaram o Pronaf & $\mathbf{9 0 \%}$ & $10 \%$ \\
\hline Famílias que não acessaram o Pronaf & $\mathbf{1 0 0} \%$ & $0 \%$ \\
\hline
\end{tabular}

Fonte: Silva (2008).

Quanto à eficiência do rendimento dos cultivos agrícolas, não se identificam grandes impedimentos técnicos nos resultados físicos. A maior limitação à implantação de cultivos agrícolas está em ataques mais freqüente de roedores e alguns insetos, sendo esta competição sempre relacionada com a fragilidade ecológica dos agroecossistemas (redução das áreas de vegetação primária).

O acesso ao crédito parece não ter causado significativas mudanças técnicas nos agroecossistemas locais, pois predominam as mesmas práticas desenvolvidas ao longo dos últimos anos. Predomina ainda o sistema de cortequeima e práticas manuais no manejo ao longo do ciclo agrícola. Uma das poucas mudanças trazidas pela presença da ATER e do financiamento foi um uso mais freqüente de herbicidas na limpeza de pastagens.

O alto grau de diversificação observado nos agroecossistemas amostrados (cerca de $80 \%$ ) contrasta com as ínfimas possibilidades de financiar propostas que fogem do padrão da pecuária extensiva.

Poucos são os agroecossistemas que não pensam em diversificar suas atividades produtivas, mas a falta de flexibilidade das linhas de financiamento fragiliza ainda mais o potencial intrínseco existente.

Das experiências de diversificação declaradas ( $40 \%$ das familias dizem ter), nenhuma delas tem relação ou apoio direto das políticas públicas presentes no assentamento. $\mathrm{O}$ mais interessante é que se trata de idéias antigas de investimentos na diversificação das atividades produtivas. Aqui cabe relembrar as experiências com o cultivo de urucum, além da busca de alternativas com as roças de baixada e do feijão "abafado". 
O único caso observado de total especialização na pecuária é de uma família em final de ciclo vital, vivendo quase exclusivamente de aposentadorias e complementando a renda com o rebanho adquirido via Pronaf (rever figura 06).

A maioria das familias conhece as atuais linhas de crédito produtivo e, por conhecer, algumas optam por não acessá-las da forma que elas são definidas. As razões para não acessarem são variadas e muito mais intrínsecas do agroecossistema: a) receio da dívida pela pouca experiência com crédito e de sua capacidade de pagamento; b) falta de flexibilidade na escolha da atividade a ser financiada e do uso dos recursos; c) não atendimento de suas demandas específicas (linhas de crédito muito homogêneas); d) em alguns casos o impedimento está na regularização da adquirida. 
Impactos do pronaf no sudeste paraense: Avaliação da sustentabilidade de agroecossistemas familiares

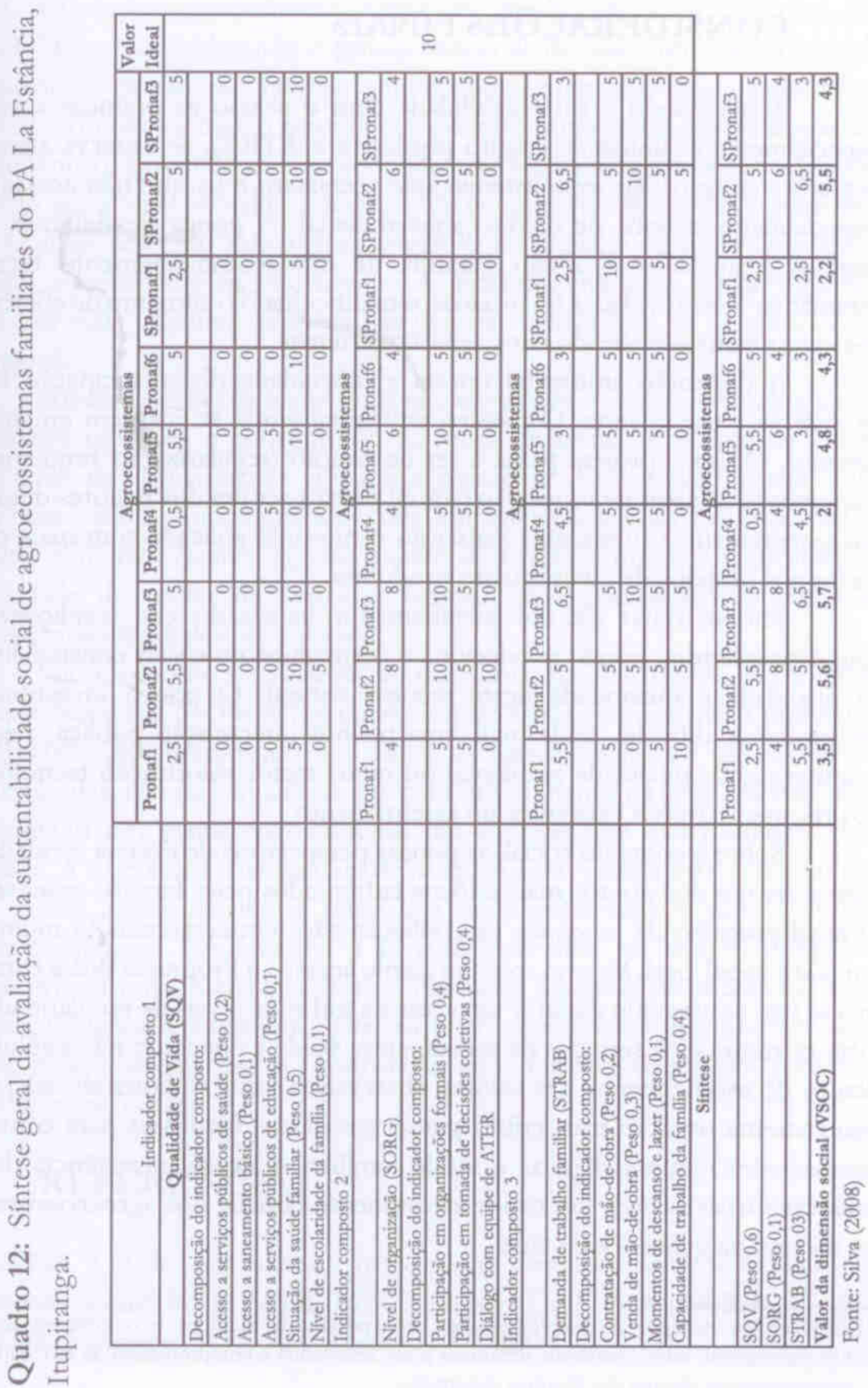




\section{CONSIDERAÇÕES FINAIS}

Relacionando a sustentabilidade com o acesso as políticas agrárias (especialmente as linhas de crédito produtivo e ATER), se observa algumas distinções entre os agroecossistemas que acessaram e os que não acessaram (especialmente a linha de crédito aqui avaliada). A pouca flexibilidade dos projetos financiados e a não garantia de um acompanhamento técnico sistemático ${ }^{21}$ das atividades financiadas, tem dificultado o aumento de eficiência dos investimentos realizados nos agroecossistemas.

A dimensão ambiental retrata a dificuldade de emancipação local do sistema corte-queima. O passivo ambiental ainda se mantém em niveis elevados. Como o projeto passa a ser de fixação (regularização fundiária), a manutenção de áreas de vegetação natural passa a ser um dos maiores desafios dos assentamentos rurais, cuja legislação vem sendo aplicada com mais rigor juntos aos projetos de investimento produtivo.

Por se tratar de um assentamento localizado em condições de abundância hídrica, pouco se relaciona o desmatamento e suas consequêencias na qualidade e quantidade deste recurso natural. $O$ pouco investimento em pesquisas dificulta ainda mais uma melhor intervenção pública, seja na manutenção da qualidade ambiental ou numa maior valorização tecnológica dos recursos naturais existentes no assentamento.

Sobre o contexto social, as poucas perspectivas de exercer a cidadania parece ser um dos pontos mais críticos enfrentados pelas familias assentadas. $\mathrm{O}$ atual processo de mudança das políticas não tem acrescentado muito ao contexto social local. Mesmo com um amplo acesso ao Programa Bolsa Familia, não se tem conseguido garantir um acesso a todos os níveis de escolaridade. A infra-estrutura e os serviços de saneamento, saúde e educação não evoluíram dentro do assentamento. Os valores observados sobre a dimensão social só não aparenta situação mais critica graças aos gastos familiares para cobrir as necessidades mínimas ligadas à saúde familiar. A quase inexistência destas políticas sociais impede um maior investimento familiar nos agroecossistemas ou mesmo na qualidade de vida.

21 Este serviço depende de convênios das cooperativas de técnicos e o governo federal. Frequientemente estes convênios demoram a ser renovados e comprometem as atividades de assessoramento técnico das famílias assentadas. 
Impactos

$\mathrm{O}$ contexto econômico parece ter modificado com o acesso ao Pronaf. Mesmo considerando o pouco tempo de investimento nas atividades produtivas, o patrimônio familiar ganhou um incremento interessante com o acesso ao crédito, mas o pagamento destes empréstimos deverá impactar futuramente os agroecossistemas endividados. Outra vantagem observada com o acesso ao crédito tem sido a redução da necessidade de venda de mão-deobra familiar, seja pelo aumento da demanda de trabalho no agroecossistema ou pela possibilidade de contratação de mão-de-obra para apoiar algumas atividades mais urgentes (limpeza das parcelas cultivadas e na renovação de pastagens).

No caso das famílias que ainda não acessaram o crédito, seu patrimônio permanece reduzido e concentrado no valor da terra, justificado na baixa capacidade de investimento no agroecossistema. Este pouco patrimônio constituido acaba comprometido com emergências ligadas principalmente à saúde familiar. Nestes agroecossistemas ainda é muito significativa à necessidade de venda do trabalho familiar, para complementar renda e reinvestir nas atividades produtivas.

Sobre o ponto de vista técnico, as limitadas alternativas de projetos de financiamentos do Pronaf parecem afetar significativamente o potencial de diversificação identificado em todos os agroecossistemas estudados. A imposição das agências financiadoras pelo investimento na pecuária não tem possibilitado um maior envolvimento das familias que não preferem esta atividade. A ausência de Instituições de pesquisa agrava ainda mais este quadro.

Nos agroecossistemas estudados ainda predomina o pouco uso de insumos externos. No entanto, a generalização dos pacotes tecnológicos tem motivado uma intensificação das atividades agrícolas via mecanização e fertilização química como única alternativa ao sistema corte-queima, sem que se investiguem alternativas já confirmadas pelas famílias assentadas (roças de baixada, entre outras).

\section{REFERENCIAS}

ALMEIDA, J. P. de. Agroecologia: nova ciência, alternativa técnico-produtiva ou movimento social? In: RUSCHEINSKY, Aluisio (Org). Sustentabilidade: uma paixão em movimento. Porto Alegre: Sulina, 2004. p.80-88 
ALONSO, A. M.; GUZMÁN, G. I. Evaluación comparada de la sostenibilidad agraria en le olivar ecológico y convencional. Agroecologia. Universidad de Murcia, v. 1, p.63-73. 2006.

ASSIS, W S. de. Organizações sociais locais e o processo de inovações no caso da agricultura familiar na Amazônia. 2001. 163 f. Dissertação (Mestrado em Agriculturas Amazônicas) - Universidade Federal do Pará. Centro Agropecuário, 2001.

ASTIER, M. S et al. El Marco de Evaluación de Sistemas de Manejo Incorporando Indicadores de Sustentabilidade (MESMIS) y su aplicación en un sistema agrícola campesino em la región purhepecha, México. In: SARADÓN, S.J (Edit.). Agroecología: el camino hacia uma agricultura sustenable. La Plata: Edicioenes Científicas, 2002. p.415-430.

BELLEN, H. M. V. Indicadores de sustentabilidade: uma análise comparativa. 2. ed. Rio de Janeiro: FGV, 2006. 256 p.

CARSON, R. L. Primavera silenciosa. Barcelona: Crítica, 2005. 255 p.

CAVALCANTE Clovis. Celso Furtado e o mito do desenvolvimento econômico. Fundação Joaquim Nabuco, 2001, 14 p. (Trabalhos para discussão, n. 104).

COLAÇO-DE-ROSARIO, M.; COSTA, A. A. M. Ensaio de avaliação da sustentabilidade do manejo do agro-eco-sistema transmontano - Norte de Portugal. Revistra Brasileira de Agroecologia, v.1, n.1, p. 75-78. 2006

CORRÊA, I V. Indicadores de sustentabilidade para agroecossistemas em transição agroecológica na região sul do Rio Grande do Sul. Pelotas-RS. 2007, 89 p. Dissertação (Mestrado em Produção Vegetal) Faculdade de Agronomia Eliseu Maciel, Universidade Federal de Pelo tas, 2007.

COSTA, G. da S. Desenvolvimento rural sustentável com base no paradigma da agroecologia. Belém, UFPA/NAEA, 2006, 381 p.

CUNHA, F. L. S.J. da. O uso de indicadores de sustentabilidade ambiental no monitoramento do desenvolvimento agrícola. 2003, 86 p. Dissertação (Mestrado em Economia) Departamento de Economia, Universidade de Brasilia, 2003. 
DE REYNAL, V. Agricultures em front pionnier amazonien, région de Marabá (Pará, Brésil). Tese (Doutorado) - INA-PG, 1999. v.1, 413 p.

DIAGNÓSTICO e plano de desenvolvimento do projeto de assentamento lastância. INCRA SR27- FATACOSERVIÇOS, Marabá, Pará, 2004, 121 p.

DOSSO, M. et al. Sistemas pedológicos e sistemas agrários em situação de fronteira pioneira amazônica. Montpellier, França: CNEARC/NAJAC/ CNRS, 1999.64 p. (Relatório científico de síntese).

EHLERS, E. Agricultura sustentável: origens e perspectivas de um novo paradigma. 2. ed. Guaíba: Agropecuária, 1999, 157 p.

ESTEVES DE VASCONCELLOS, M.J. Pensamento sistêmico: o novo paradigma da ciência. 6. ed. Campinas, SP: Papirus, 2002. 260 p.

FUNTOWICZ, S.; DE MARCHI, B. Ciencia posnormal, complexidad reflexiva, y sustentabilidad. In: LEFF, Enrique (coord.). La complexidad ambiental. México, D. F: Siglo veitiuno, 2000. p. 54-84.

HOMMA, A. K. O. Amazônia: como aproveitar os benefícios da destruição. Estudos Avançados, São Paulo, v.54, n.19, p. 115-135. 2005.

KAGEYAMA, Ângela. Produtividade e renda na agricultura familiar: efeitos do Pronaf - crédito. Agricultura São Paulo, São Paulo, v. 50, n. 2, p. 1-13. 2003.

KITAMURA, P. C. A Amazônia e o desenvolvimento sustentável. EMBRAPAjCPATU, Belém, 1994, 182p.

LEFF, E. Racionalidade ambiental: a re-apropriação social da natureza. Rio de Janeiro: Civilização brasileira, 2006. 555p.

LIMA, D.; POZZOBON, J. Amazônia socioambiental: sustentabilidade ecológica e diversidade social. Estudos Avançados, São Paulo, v.54, n.19, p. $45-76,2005$.

LUTZENBERGERJ. A. Fim do futuro?: manifesto ecológico brasileiro. Porto Alegre, Movimento, UFRG, 1980, 98 p. 
Luis Mauro Santos Silva e Sérgio Roberto Martins

MARTINS, S.R. Limites del desarrollo sostenible para América Latina en el marco de Ias políticas de (re)ajuste económico. Pelotas: UFPEL, 1997. 139p.

MARTINS, S.R. É possivel construir conhecimento agroecológico sem pensamento agroecológico? CONGRESSO INTERNACIONAL DE AGroECOLOGIA, 9, 2008, Porto Alegre. Palestra. . Porto Alegre :EMATER,2008

MASERA, O; ASTIER, M.; LOPEZ-RIDAURA, S. Sustentabilidad y manejo de recursos naturales: el marco de evaluación MESMIS. GIRA, México, 1999.109 p.

MARZALL, K. Indicadores de sustentabilidade para agroecossistemas. 1999, 214 f. Dissertação (Mestrado em Desenvolvimento Rural) - PGDR, Universidade Federal do Rio Grande do Sul, Porto Alegre.

MAZOIER, M.; ROUDAT, L. Histoire des agricultures dumonde: du néolithique à la crise contemporaine. Paris: Seuil, 1997, 534 p.

MINISTÉRIO DO DESENVOLVIMENTO SOCIAL. http://www. mds.gov.br/bolsafamilia/o_programa_bolsajarnilia/o-que-e/, acesso em 14.07.2008.

MONTIBELLER, F. G. O mito do desenvolvimento sustentável: meio ambiente e custos sociais no moderno sistema produtor de mercadorias. 2. ed. Revisada. Florianópolis: Ed. da UFSC, 2004. 306 p.

MORIN, E. Introdução ao pensamento complexo. Tradução de Eliane Lisboa - Porto Alegre: Sulina, 2005. 120 p.

SARANDÓN, S. J. et al.. Evaluación de Ia sustentabilidad de sistemas agrícolas de fincas en Misiones, argentina, mediante el uso de indicadores. Agroecologia. Facultad de Biologia - Universidad de Murcia: v. 1, p. 19-28, 2006.

SILVA, L. G. T. Sustentabilidade da agricultura familiar em assentamentos rurais oficiais do sudeste paraense. 2007, 295 f. Tese (Doutorado em Desenvolvimento Sustentável do Trópico Úmido) - NAEA, Universidade Federal do Pará, Belém. 
SILVA, L. M. S. Impactos do crédito produtivo nas noções locais de sustentabilidade em agroecossistemas familiares no território sudeste do Pará. 2008, 203 f.. Tese (Doutorado em Produção Vegetal) Faculdade de Agronomia Eliseu Maciel, Universidade Federal de Pelotas, Pelotas.

OLIVEIRA, P. de. Mudanças nos Parâmetros Técnicos dos Projetos de Crédito Rural: O Caso dos Projetos de Assentamentos no Sudeste do Pará. 2005, 110 f.. Dissertação (Mestrado em Agriculturas Familiares e Desenvolvimento Sustentável) - Centro Agropecuário, Universidade Federal do Pará e Embrapa Amazônia Oriental, Belém.

SEN, A. Desenvolvimento como liberdade. São Paulo: Companhia das letras, 2000.409 p.

TURA, L. R et al. Campesinato e Estado na Amazônia: impactos do FNO no Pará . Editora BrasiliaJurídica: FASE, 2000. 381p.

VAN BELLEN, H. M. Indicadores de sustentabilidade: uma análise comparativa. 2002, $220 \mathrm{f}$. Tese (Doutorado) - UFSC.

VEIGA, J. E. da. Desenvolvimento sustentável: o desafio do século XXI. Rio de Janeiro: Garamond, 2005. 220 p.

VERONA, L. A. F Avaliação da sustentabilidade em agroecossistemas de base familiar e em transição agroecológica na região sul do Rio Grande do Sul. 2008, 193 f.. Tese (Doutorado em Produção Vegetal) - Faculdade de Agronomia Eliseu Maciel, Universidade Federal de Pelotas, Pelotas.

VIEIRA, L C. de. Estratégias para evitar a perda de biodiversidade na Amazônia. Estudos avançados, Sã Paulo, v.54, n. 19, p.153-164. 2005. 


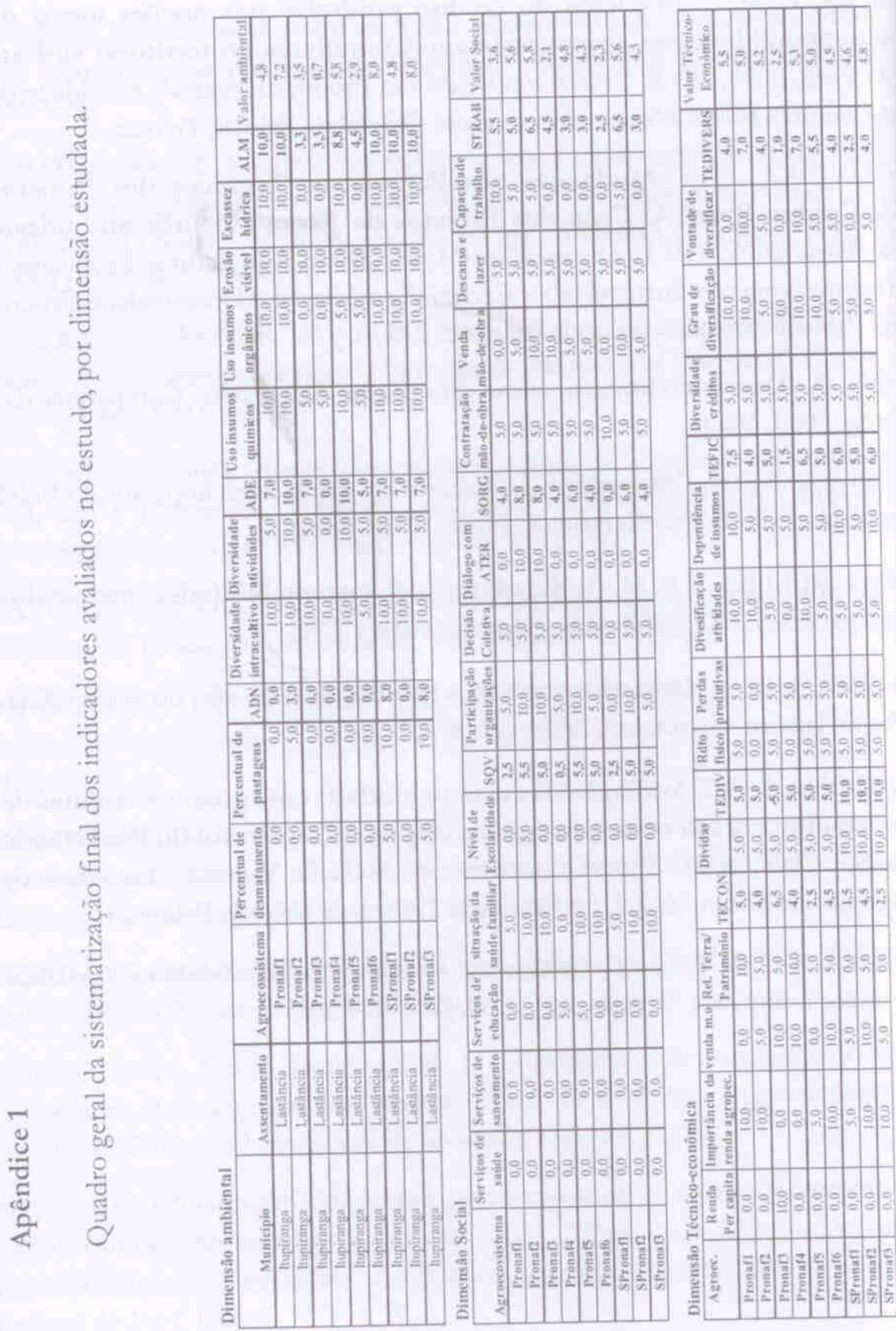

